\title{
Study of Supramolecular Side-Chain Copolymers Containing Light-Emitting H-Acceptors and Electron-Transporting Dendritic H-Donors
}

\author{
Po-Jen Yang, Chung-Wen Wu, Duryodhan Sahu, and Hong-Cheu Lin* \\ Department of Materials Science and Engineering, National Chiao Tung University, Hsinchu, Taiwan, ROC
}

Received May 3, 2008; Revised Manuscript Received October 27, 2008

\begin{abstract}
A novel light-emitting hydrogen-bonded (H-) acceptor PBB (M1) containing three conjugated aromatic rings, including one pyridyl terminus and two lateral methoxyl groups (on the middle ring), was successfully synthesized via Horner-Wadsworth-Emmons (HWE) olefination and Sonogashira coupling reaction. Moreover, different molar ratios of light-emitting H-acceptor monomer PBB (M1) and hole-transporting monomer CAZ (M2) bearing a carbazole unit were copolymerized through free radical polymerization to obtain lightemitting and hole-transporting H-acceptor copolymers (P1-P5). H-acceptor copolymers P3 and P4 were complexed with different generations of dendritic H-donors $(\mathbf{G 1 C O O H}-\mathbf{G 3 C O O H})$ bearing 1,3,4-oxadiazole $(\mathbf{O X D})$ dendrons and terminal benzoic acids via H-bonded self-assembly to form supramolecular side-chain copolymers (i.e., H-bonded dendritic complexes). In contrast to H-acceptor homopolymer P1 (HPBB), H-acceptor copolymers P2-P4 incorporated with carbazole $(\mathbf{C A Z})$ moieties effectively enhance the glass transition temperatures $\left(T_{\mathrm{g}} \mathrm{s}\right)$ and minimize the interchain interations of the light-emitting $\mathrm{H}$-acceptor units, and similar effects occur in their $\mathrm{H}$-bonded dendritic complexes. In addition, red shifts of photoluminescence (PL) emissions in H-bonded dendritic complexes can be tuned up to $61 \mathrm{~nm}$. Furthermore, H-bonded dendritic complexes excited at $305 \mathrm{~nm}$ of OXD absorption can create a stronger fluorescence than that excited at $397 \mathrm{~nm}$ of PBB absorption, indicating that the intensity of the sensitized emission of PBB (by energy transfer from OXD absorption at $305 \mathrm{~nm}$ ) is even stronger than that of a direct emission of PBB (by merely PBB absorption at $397 \mathrm{~nm}$ ). The OXD dendritic wedges in H-bonded dendritic complexes can lower the LUMO energy levels and provide a better electron injection property. $\mathrm{H}$-acceptor polymer $\mathbf{P 4}$ and its H-bonded dendritic complexes showed electroluminescence (EL) emissions in the range of 464-519 $\mathrm{nm}$ from blue to green. In addition, a PLED device containing H-bonded dendritic complex P4/G1COOH showed an EL emission of $519 \mathrm{~nm}$ under a turn-on voltage of $6.5 \mathrm{~V}$, with a maximum luminance of $408 \mathrm{~cd} / \mathrm{m}^{2}$ at $18 \mathrm{~V}$ and a luminance efficiency of $0.39 \mathrm{~cd} / \mathrm{A}$ at $100 \mathrm{~mA} / \mathrm{cm}^{2}$, respectively.
\end{abstract}

\section{Introduction}

In recent years, polymeric materials based on spontaneous formation of supramolecular architectures by self-assembly of various organic molecular components have attracted great attention in areas ranging from chemistry to materials science. ${ }^{1,2}$ Simple association of two complementary compounds through specific noncovalent interactions, such as hydrogen-bonded $(\mathrm{H}-$ bonded), ${ }^{3-8}$ ionic, ${ }^{9,10}$ and metal-coordinative ${ }^{11-15}$ interactions between molecular components, can give rise to unique properties and phase structures, which are not possessed by the individual components. Intensive researches have been directed toward functional supramolecular systems to control the dimensionality and shape of self-assembled structures through molecular design, but it remains a challenge driven by a wide variety of potential applications in the fields of catalyzes, microelectronics, nonlinear optics, sensors, and display technologies.

Since the first polymeric light-emitting diode (PLED) based on poly( $p$-phenylenevinylene) (PPV) was reported by Burroughes et al., ${ }^{16}$ various kinds of conjugated main-chain and side-chain polymers have been developed for electroluminescent (EL) devices. ${ }^{17-20}$ Future applications of PLEDs to full-color and large-area flat panel displays become possible due to their high luminescence efficiency, low cost, high flexibility, and easy fabrication of spin-coating technique. ${ }^{21}$ However, the most important problem with the $\pi$-conjugated systems is their tendency to form aggregates/excimers via $\pi-\pi$ interactions in the solid state, which will lead to red shifts or low-energy band

* Corresponding author: Tel 8863-5712121ext 55305; Fax 88635724727; e-maillinhc@mail.nctu.edu.tw. gaps of emission spectra, self-quenching of excitons, and reduction of fluorescence quantum efficiencies. To overcome this problem, one of the approaches is to introduce dendritic architectures into the $\pi$-conjugated systems so as to prevent close chains from packing and thus to increase the polymer luminescent efficiency and reduce the tendency of aggregation. For instance, Fréchet-type poly(aryl ether) dendrons attached to fluorene units were reported by Carter et al. ${ }^{22}$ to demonstrate the shielding effect by attaching dendritic side chains to the conjugated polyfluorene backbones, which improved the luminescence properties of these materials due to the reduction of both aggregates/excimers in solution and solid states. Müllen et al. ${ }^{23}$ prepared polyfluorene-based conjugated polymers with bulky polyphenylene dendritic substituents at C-9 position, which suppressed the formation of aggregates with long wavelength emissions, and thus a pure blue emission was acquired. More recently, a number of dendrimers have been reported for a wide variety of applications in such EL device $^{24-34}$ and photovoltaic (PV) cell ${ }^{35,36}$ materials.

In our previous work, ${ }^{37} \mathrm{H}$-donor dendrimers with a benzoic acid terminus were singly/doubly H-bonded to mono/bis-pyridyl $\mathrm{H}$-acceptor emitters to form several series of novel supramolecular dendrimers, whose emission colors could be easily adjusted by their non-light-emitting $\mathrm{H}$-donors. Moreover, the higher generation of dendritic sizes could afford stronger siteisolation and dendron-dilution effects, so better energy transfer along with higher fluorescence quantum efficiencies were achieved.

In the present study, our strategy is to extend the $\pi$-conjugated system from $\mathrm{H}$-acceptor emitters of small molecules to lightemitting $\mathrm{H}$-acceptor polymers. According to Scheme 1, a series 
Scheme 1. Synthetic Routes of H-Acceptor Monomer and Polymers (P1-P5) ${ }^{a}$

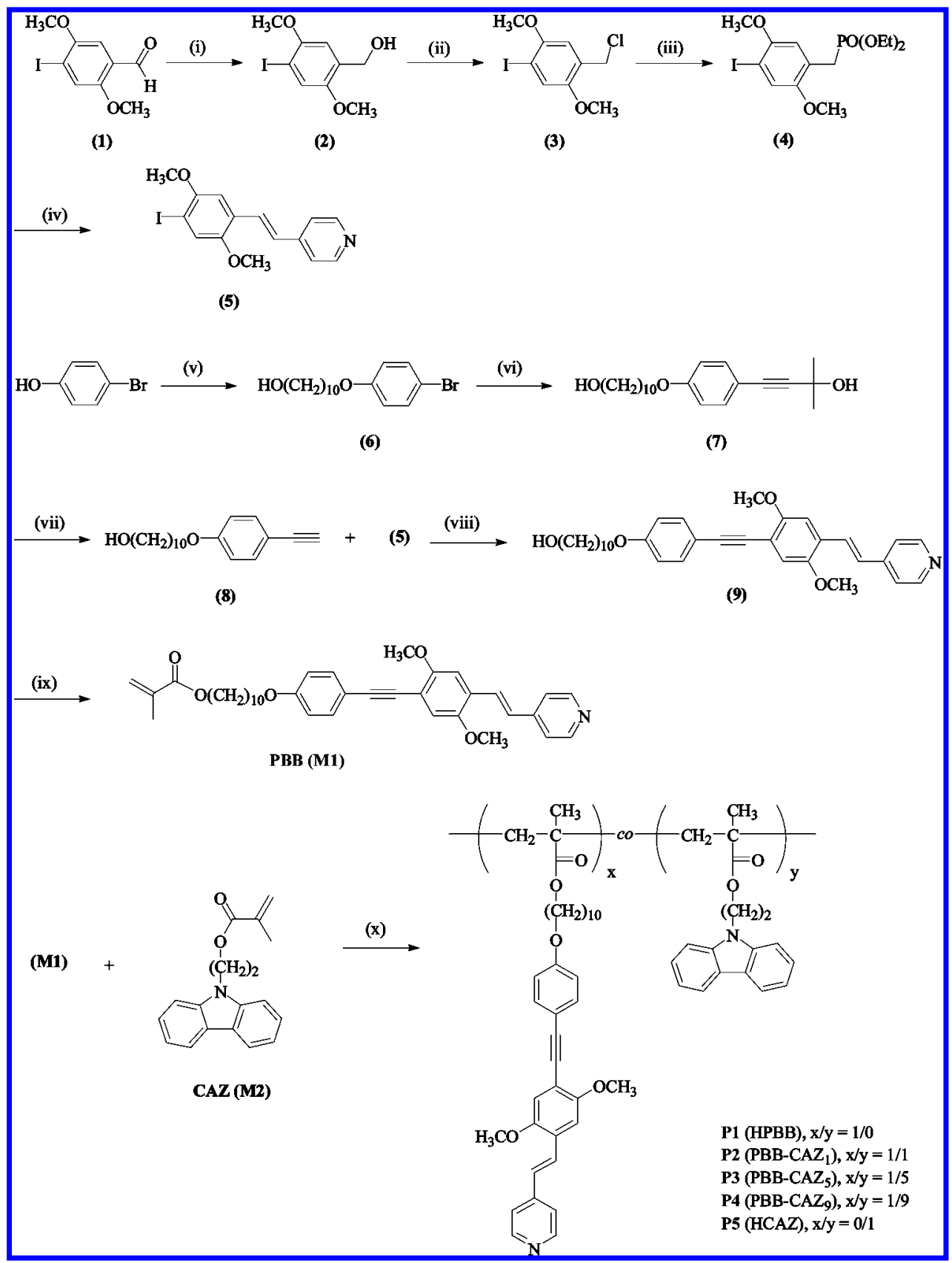

${ }^{a}$ Reagents and conditions: (i) $\mathrm{NaBH}_{4}, \mathrm{MeOH} / \mathrm{THF}$, room temperature, $1 \mathrm{~h}$; (ii) concentrated $\mathrm{HCl}$, dioxane, reflux, $10 \mathrm{~h}$; (iii) $\mathrm{P}(\mathrm{OEt})_{3}$, reflux, $12 \mathrm{~h}$; (iv) pyridine-4-carboxaldehyde, $t$-BuOK, THF, room temperature, $12 \mathrm{~h}$; (v) 10-bromodecanol, $\mathrm{K}_{2} \mathrm{CO}_{3}, \mathrm{KI}$, acetone, reflux, $48 \mathrm{~h}$; (vi) 2 -methyl3-butyn-2-ol, $\mathrm{Pd}\left(\mathrm{PPh}_{3}\right)_{2} \mathrm{Cl}_{2}, \mathrm{CuI}, \mathrm{PPh}_{3}, \mathrm{Et}_{3} \mathrm{~N}, 70{ }^{\circ} \mathrm{C}, 12 \mathrm{~h}$; (vii) $\mathrm{KOH}$, dioxane, reflux, $3 \mathrm{~h}$; (viii) $\mathrm{Pd}\left(\mathrm{PPh}_{3}\right)_{2} \mathrm{Cl}_{2}, \mathrm{CuI}, \mathrm{PPh}_{3}, \mathrm{Et}_{3} \mathrm{~N} / \mathrm{THF}, 50{ }^{\circ} \mathrm{C}$, overnight; (ix) vinyl methacrylate, 1,3-dichloro-1,1,3,3-tetrabutyldistannoxane, 2,6-di-tert-butyl-4-methylphenol, THF, $50{ }^{\circ} \mathrm{C}, 48 \mathrm{~h}$; (x) $\mathrm{AIBN}$, THF, $60{ }^{\circ} \mathrm{C}$, $24 \mathrm{~h}$.

of novel homopolymeric and random-copolymeric $\mathrm{H}$-acceptor emitters containing carbazole moieties (to increase $T_{\mathrm{g}}$ values and hole-transporting properties of PLEDs) and three-conjugated aromatic rings, including one pendent pyridyl terminus (as the $\mathrm{H}$-acceptor site) and two lateral methoxyl groups on the middle rings (to increase solubility after polymerization), were successfully synthesized. By incorporating with different generations of OXD dendritic H-donors bearing benzoic acids (see Figure 1), the supramolecular side-chain copolymers (i.e., H-bonded dendritic complexes) were consecutively constructed as shown in Figure 2. Hopefully, supramolecular dendrimers bearing light-emitting $\mathrm{H}$-acceptor polymers (in comparison with small molecular emitters) will have a better film-forming property by the spin-coating process, which may eventually be more useful in PLED device applications. Accordingly, Hbonded effects on the thermal, photophysical, and photo/ electroluminescent properties of these supramolecules in the solid state will be illustrated.

\section{Experimental Section}

Measurements and Characterization. ${ }^{1} \mathrm{H}$ NMR spectra were recorded on a Varian Unity $300 \mathrm{MHz}$ spectrometer using $\mathrm{CDCl}_{3}$ and DMSO- $d_{6}$ as solvents. Elemental analyses were performed on a HERAEUS CHN-OS RAPID elemental analyzer. High-resolution electron impact mass data were obtained on a Finnigan-MAT-95XL. Phase transition temperatures were determined by differential scanning calorimetry (DSC, model: Perkin-Elmer Diamond) under $\mathrm{N}_{2}$ with a heating and cooling rate of $10{ }^{\circ} \mathrm{C} / \mathrm{min}$ and polarizing 


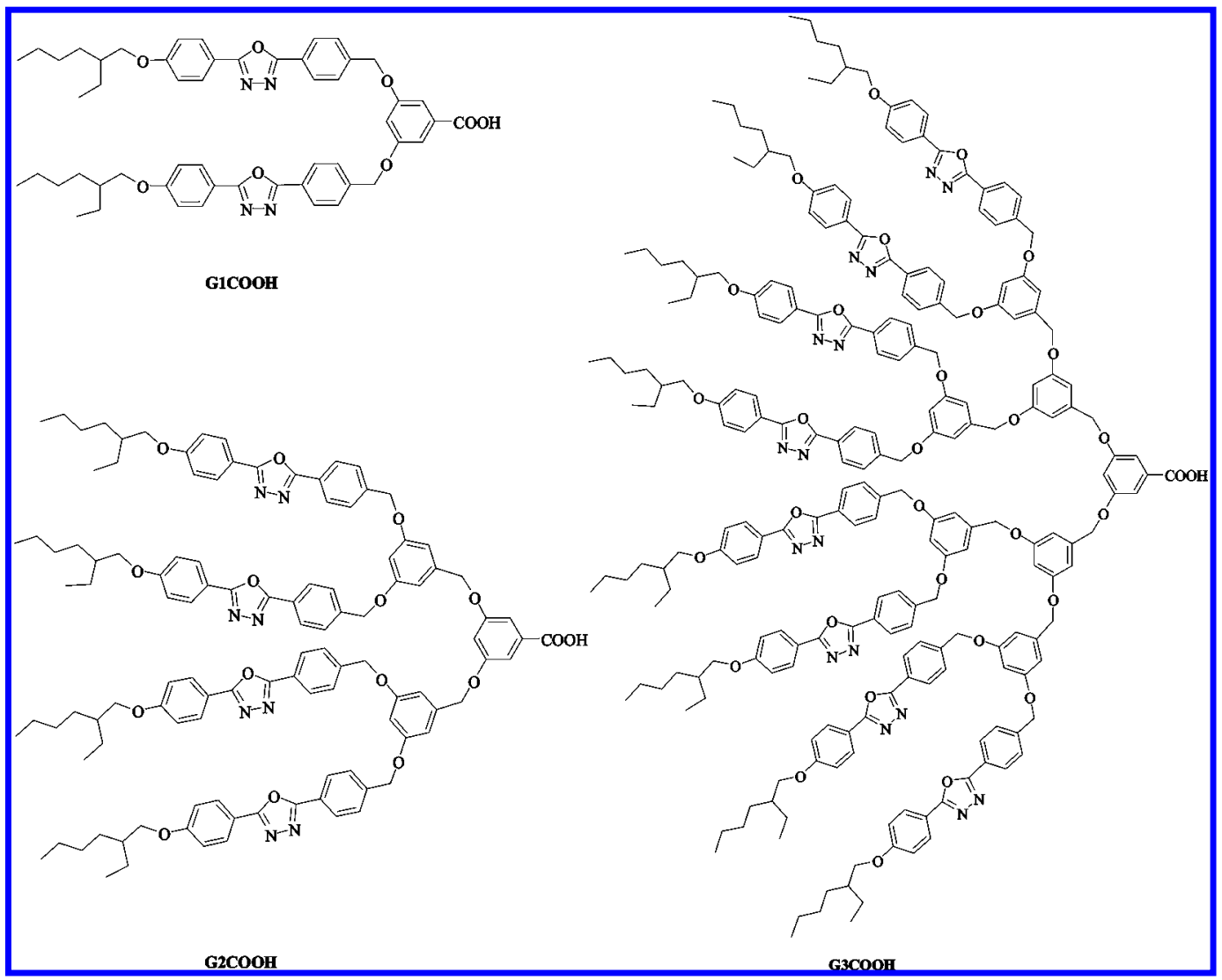

Figure 1. Different generations of dendritic H-donors $(\mathbf{G 1 C O O H}-\mathbf{G} 3 \mathbf{C O O H})$ used in H-bonded side-chain dendritic complexes.

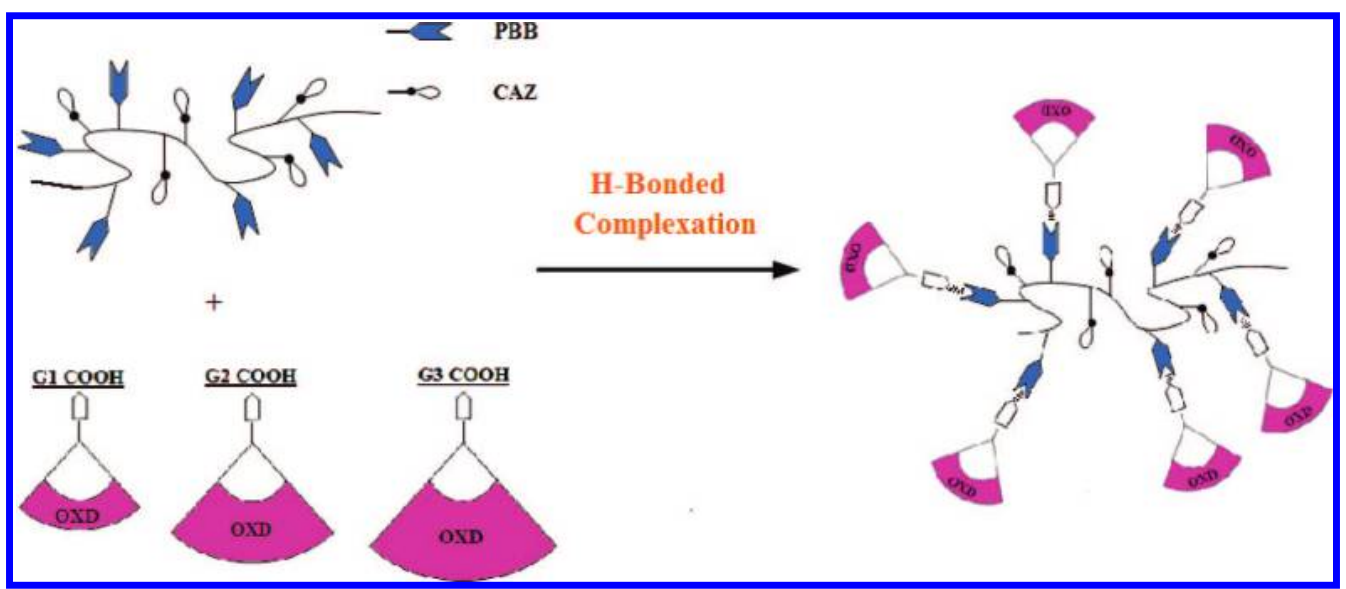

Figure 2. Schematic representation of $\mathrm{H}$-acceptor copolymers and $\mathrm{H}$-bonded side-chain dendritic complexes bearing different generations of dendritic H-donors $(\mathbf{G 1 C O O H}-\mathbf{G 3 C O O H})$.

optical microscope (POM, model: Leica DMLP) equipped with a hot stage. Thermogravimetric analyses (TGA) were carried out on a TA Instruments Q500 thermogravimetric analyzer at a heating rate of $20^{\circ} \mathrm{C} / \mathrm{min}$ under nitrogen. Gel permeation chromatography (GPC) analyses were conducted on a Waters 1515 separation module using polystyrene as a standard and THF as an eluant. Fourier transform infrared (FTIR) spectra of samples (dispersed in $\mathrm{KBr}$ disks) were recorded on a Perkin-Elmer Spectrum 100 Series. Synchrotron powder X-ray diffraction (XRD) measurements were performed at the beamline BL17A of the National Synchrotron Radiation Research Center (NSRRC), Taiwan (for details of the XRD installation, see Supporting Information). UV-vis absorption spectra were recorded on a HP G1103A spectrophotometer, and photoluminescence (PL) spectra were obtained on a Hitachi F-4500 spectrophotometer in dilute THF solutions $\left(10^{-6} \mathrm{M}\right)$. The PL quantum yields $\left(\Phi_{\mathrm{PL}}\right)$ of polymers were measured with $9,10-$ diphenylanthracene as a reference (in cyclohexane, $\left.\Phi_{\mathrm{PL}}=0.9\right){ }^{38}$
Thin films in UV-vis and PL measurements were prepared by spincoating of THF solutions (with a concentration of $10 \mathrm{mg} / \mathrm{mL}$ ) at $3000 \mathrm{rpm}$ on a quartz substrate. Cyclic voltammetry (CV) measurements were performed at a scanning rate of $100 \mathrm{mV} / \mathrm{s}$ in a solution of $0.1 \mathrm{M}$ tetrabutylammonium hexafluorophosphate $\left(\mathrm{Bu}_{4} \mathrm{NPF}_{6}\right)$ dissolved in acetonitrile at room temperature using an Autolab PGSTAT30 potentiostat/galvanostat with a standard three-electrode electrochemical cell. A platinum disk working electrode, a Pt wire counter electrode, and an $\mathrm{Ag} / \mathrm{AgCl}$ reference electrode were used. The sample films were coated on the surface of a platinum disk by the solution-dipping process from THF solutions.

A series of electroluminescence (EL) devices with the configuration of ITO/PEDOT:PSS/polymer (P4 or its H-bonded dendrimers complexes)/BCP/Alq $3 / \mathrm{LiF} / \mathrm{Al}$ were made, where $\mathrm{BCP}$ (i.e., 2,9-dimethyl-4,7-diphenyl-1,10-phenanthroline) was used as a holeblocking layer and $\mathrm{Alq}_{3}$ (i.e., tris(8-hydroxyquinoline)aluminum) was used as an electron-transporting layer. ITO substrates, where 
glass substrates were coated with indium-tin oxide (ITO) having a sheet resistance of $\sim 20 \Omega$ /square and an effective individual device area of $3.14 \mathrm{~mm}^{2}$, were routinely cleaned by ultrasonic treatments in detergent solutions and diluted water, followed by rinsing with acetone and then ethanol. After drying, ITO substrates were kept in oxygen plasma for 4 min before being loaded into the vacuum chamber. The poly(3,4-ethylenedioxythiophene):poly(styrenesulfonate) (PEDOT:PSS) films were first deposited on precleaned ITO substrates by spin-coating at $6000 \mathrm{rpm}$ for $1 \mathrm{~min}$ and subsequently cured in an oven at $120{ }^{\circ} \mathrm{C}$ for $1 \mathrm{~h}$. Then, lightemitting polymers (P4 or its $\mathrm{H}$-bonded side-chain dendritic complexes) in THF solutions $(10 \mathrm{mg} / \mathrm{mL})$ were spin-coated onto the PEDOT:PSS layer at 4000-5500 rpm. The thicknesses of PEDOT:PSS and LED polymers were measured by an Alfa Step 500 surface profiler (Tencor). $\mathrm{BCP}$ and $\mathrm{Alq}_{3}$ were thermally deposited at a rate of $1-2 \AA / \mathrm{s}$ under a pressure of $\sim 2 \times 10^{-5}$ Torr in an Ulvac cryogenic deposition system. Under the same deposition condition, one layer of $\mathrm{LiF}$ was thermally deposited as a cathode at a rate of $0.1-0.2 \AA / \mathrm{s}$, which was followed by capping with aluminum. The current-voltage-luminescence characteristics were measured in ambient condition by a Keithley 2400 source meter and a Newport $1835 \mathrm{C}$ optical meter equipped with an 818ST silicon photodiode.

Materials. Chemicals and solvents were reagent grades and purchased from Aldrich, ACROS, TCI, and Lancaster Chemical Co. Tetrahydrofuran (THF) and triethylamine $\left(\mathrm{Et}_{3} \mathrm{~N}\right)$ were distilled to keep anhydrous before use. Azobis(isobutyronitrile) (AIBN) was recrystallized from methanol before use. The other chemicals were used without further purification. Different generations of dendritic H-donors (G1COOH-G3COOH), as shown in Figure 1, used in $\mathrm{H}$-bonded side-chain dendritic complexes were reported in our previous work. ${ }^{37} 10$-Bromodecanol, ${ }^{39}$ 1,3-dichloro-1,1,3,3-tetrabutyldistannoxane, ${ }^{40}$ and monomer CAZ (M2) ${ }^{41}$ were prepared by following the already published procedures.

4-Iodo-2,5-dimethoxybenyl Alcohol (2). To a stirred solution of 4-iodo-2,5-dimethoxybenzaldehyde, 1 (8.0 g, $27.4 \mathrm{mmol}$ ), in 200 $\mathrm{mL}$ of THF/MeOH (1:1), $\mathrm{NaBH}_{4}(0.52 \mathrm{~g}, 13.7 \mathrm{mmol})$ was added very slowly to react at room temperature. After $1 \mathrm{~h}$, the solution was cooled to $0{ }^{\circ} \mathrm{C}$ by ice bath, acidified with dilute $\mathrm{HCl}$ solution, and extracted with ethyl acetate. The resulting materials in organic phase were combined and washed with water. Afterward, the organic extracts were dried over $\mathrm{Na}_{2} \mathrm{SO}_{4}$ and evaporated. The purified residue was recrystallized from dichloromethane/2-propanol to give a colorless crystal. Yield: $7.6 \mathrm{~g}(95 \%) .{ }^{1} \mathrm{H}$ NMR $(300 \mathrm{MHz}$, $\left.\mathrm{CDCl}_{3}\right): \delta(\mathrm{ppm}) 7.25(\mathrm{~s}, 1 \mathrm{H}), 6.85(\mathrm{~s}, 1 \mathrm{H}), 4.65(\mathrm{~d}, J=6.3 \mathrm{~Hz}$, $2 \mathrm{H}), 3.85(\mathrm{~s}, 3 \mathrm{H}), 3.82(\mathrm{~s}, 3 \mathrm{H}), 2.22(\mathrm{t}, J=6.6 \mathrm{~Hz}, 1 \mathrm{H})$.

1-Iodo-4-chloromethyl-2,5-dimethoxybenzene (3). To a stirred solution of $2(7.0 \mathrm{~g}, 23.8 \mathrm{mmol})$ in 1,4-dioxane $(200 \mathrm{~mL})$, concentrated $\mathrm{HCl}(20 \mathrm{~mL})$ was added to reflux for $10 \mathrm{~h}$. After the reaction was completed, the crude mixture was added with water. The organic layer was extracted with ethyl acetate, dried over $\mathrm{Na}_{2} \mathrm{SO}_{4}$, and evaporated. The residual product was purified by flash column chromatography (silica gel, $n$-hexane/ethyl acetate 40:1) to give a white solid. Yield: $6.8 \mathrm{~g}(92 \%) .{ }^{1} \mathrm{H}$ NMR $(300 \mathrm{MHz}$, $\left.\mathrm{CDCl}_{3}\right): \delta(\mathrm{ppm}) 7.29(\mathrm{~s}, 1 \mathrm{H}), 6.86(\mathrm{~s}, 1 \mathrm{H}), 4.60(\mathrm{~s}, 2 \mathrm{H}), 3.85(\mathrm{~s}$, $3 \mathrm{H}), 3.83$ (s, $3 \mathrm{H})$.

4-Iodo-2,5-dimethoxybenzyldiethylphosphonate (4). Compound 3 (6.0 g, $19.2 \mathrm{mmol}$ ) was mixed with an excess of triethyl phosphite $(20 \mathrm{~mL})$, and the mixture was heated to reflux and reacted for $12 \mathrm{~h}$. The excess of triethyl phosphite was removed under reduced pressure, and the crude product was purified by washing with hot hexane to give a white solid. Yield: $7.2 \mathrm{~g}(90 \%) .{ }^{1} \mathrm{H}$ NMR $(300$ $\left.\mathrm{MHz}, \mathrm{CDCl}_{3}\right): \delta(\mathrm{ppm}) 7.25(\mathrm{~s}, 1 \mathrm{H}), 6.9(\mathrm{~s}, 1 \mathrm{H}), 4.08-3.99(\mathrm{~m}$, $4 \mathrm{H}), 3.83(\mathrm{~s}, 3 \mathrm{H}), 3.80(\mathrm{~s}, 3 \mathrm{H}), 3.20(\mathrm{~d}, J=21.6 \mathrm{~Hz}, 2 \mathrm{H}), 1.24(\mathrm{t}$, $6.9 \mathrm{~Hz}, 6 \mathrm{H})$.

1-Iodo-2,5-dimethoxy-4-[2-(4-pyridyl)ethenyl]benzene (5). To a solution of pyridine-4-carboxaldehyde $(1.86 \mathrm{~g}, 17.4 \mathrm{mmol})$ in anhydrous THF $(10 \mathrm{~mL})$, a suspension of 4 (6.0 g, $14.5 \mathrm{mmol})$ and $t$-BuOK $(2.93 \mathrm{~g}, 26.1 \mathrm{mmol})$ in anhydrous THF $(60 \mathrm{~mL})$ under nitrogen was slowly added. The mixture was stirred to react at room temperature for $12 \mathrm{~h}$. After the reaction was completed, it was quenched with water and extracted with dichloromethane. After that, the organic layer was dried over $\mathrm{Na}_{2} \mathrm{SO}_{4}$ and evaporated. The crude product was purified by column chromatography (silica gel, dichloromethane/acetone 30:1) to give a yellow solid. Yield: $3.2 \mathrm{~g}$ (60\%). ${ }^{1} \mathrm{H}$ NMR $\left(300 \mathrm{MHz}, \mathrm{CDCl}_{3}\right): \delta(\mathrm{ppm}) 8.55$ (d, $J=4.5 \mathrm{~Hz}$, $2 \mathrm{H}), 7.57(\mathrm{~d}, J=16.5 \mathrm{~Hz}, 1 \mathrm{H}), 7.37(\mathrm{~d}, J=4.5 \mathrm{~Hz}, 2 \mathrm{H}), 7.30(\mathrm{~s}$, $1 \mathrm{H}), 7.01(\mathrm{~d}, J=16.5 \mathrm{~Hz}, 1 \mathrm{H}), 7.00(\mathrm{~s}, 1 \mathrm{H}), 3.88$ (s, 3H), 3.84 (s, $3 \mathrm{H})$.

10-(4-Bromophenoxy)decan-1-ol (6). To a stirred solution of 4-bromophenol (4.0 g, $23.1 \mathrm{mmol})$ in acetone $(200 \mathrm{~mL})$, potassium carbonate (9.6 g, $69.3 \mathrm{mmol})$, 10-bromodecanol (6.6 g, $27.7 \mathrm{mmol})$, and a few amounts of potassium iodide (ca. $10 \mathrm{mg}$ ) were added to reflux for $48 \mathrm{~h}$ under nitrogen. After cooling to room temperature, the solvent was removed under reduced pressure, and the residue was taken up in water and extracted with ethyl acetate. Next, the organic layer was dried over $\mathrm{Na}_{2} \mathrm{SO}_{4}$ and evaporated. The crude product was purified by column chromatography (silica gel, $n$-hexane/ethyl acetate 3:1) to give a white solid. Yield: $6.1 \mathrm{~g}(80 \%)$. ${ }^{1} \mathrm{H}$ NMR (300 MHz, $\left.\mathrm{CDCl}_{3}\right): \delta(\mathrm{ppm}) 7.33(\mathrm{~d}, J=9.0 \mathrm{~Hz}, 2 \mathrm{H})$, $6.75(\mathrm{~d}, J=9.0 \mathrm{~Hz}, 2 \mathrm{H}), 3.89(\mathrm{t}, J=6.3 \mathrm{~Hz}, 2 \mathrm{H}), 3.62(\mathrm{t}, J=6.6$ $\mathrm{Hz}, 2 \mathrm{H}), 1.78-1.69$ (m, 2H), 1.59-1.50 (m, 2H), 1.41-1.29 (m, $12 \mathrm{H})$.

4-[4-(10-Hydroxydecyloxy)phenyl]-2-methyl-3-butyn-2-ol (7). A solution of 6 (4.0 g, $12.1 \mathrm{mmol}), \mathrm{PPh}_{3}(63.1 \mathrm{mg}, 0.24 \mathrm{mmol})$, and $\mathrm{CuI}(45.6 \mathrm{mg}, 0.24 \mathrm{mmol})$ in $\operatorname{dry} \mathrm{Et}_{3} \mathrm{~N}(80 \mathrm{~mL})$ was degassed with nitrogen for $5 \mathrm{~min}$. Then, the solution was added with 2-methyl3-butyn-2-ol (2.0 g, $24.2 \mathrm{mmol})$ and $\mathrm{Pd}\left(\mathrm{PPh}_{3}\right)_{2} \mathrm{Cl}_{2}(84.1 \mathrm{mg}, 0.12$ $\mathrm{mmol})$ at room temperature, and the reaction mixture was stirred to react at $70{ }^{\circ} \mathrm{C}$ for $12 \mathrm{~h}$. The mixture was filtered, and the solvent was removed in vacuum. The crude mixture was extracted using ethyl acetate, and the extract was washed with water, dried over $\mathrm{Na}_{2} \mathrm{SO}_{4}$, and then evaporated. Subsequently, the crude product was purified by column chromatography (silica gel, $n$-hexane/ethyl acetate $1: 1)$ to give a light yellow solid. Yield: $3.14 \mathrm{~g}(78 \%) .{ }^{1} \mathrm{H}$ NMR (300 MHz, $\left.\mathrm{CDCl}_{3}\right): \delta(\mathrm{ppm}) 7.31(\mathrm{~d}, J=9.0 \mathrm{~Hz}, 2 \mathrm{H}), 6.79$ $(\mathrm{d}, J=9.0 \mathrm{~Hz}, 2 \mathrm{H}), 3.92(\mathrm{t}, J=6.6 \mathrm{~Hz}, 2 \mathrm{H}), 3.62(\mathrm{t}, J=6.6 \mathrm{~Hz}$, $2 \mathrm{H}), 1.77-1.70(\mathrm{~m}, 2 \mathrm{H}), 1.60(\mathrm{~s}, 6 \mathrm{H}), 1.58-1.50(\mathrm{~m}, 2 \mathrm{H})$, $1.42-1.29(\mathrm{~m}, 12 \mathrm{H})$.

4-Ethynyl-1-(10-hydroxydecan-1-yloxy)benzene (8). A stirred solution of 7 (2.5 g, $7.5 \mathrm{mmol})$ and finely powdered $\mathrm{KOH}(1.26 \mathrm{~g}$, $22.5 \mathrm{mmol})$ in 1,4-dioxane $(80 \mathrm{~mL})$ was refluxed under nitrogen for $3 \mathrm{~h}$. After cooling to room temperature, the solvent was removed under reduced pressure and the residue was taken up in water, and then the mixture was extracted with ethyl acetate and acidified with $3 \mathrm{~N} \mathrm{HCl}(150 \mathrm{~mL})$. The organic solution was washed with water, dried over $\mathrm{Na}_{2} \mathrm{SO}_{4}$, and then evaporated. Afterward, the crude product was purified by column chromatography (silica gel, $n$-hexane/ethyl acetate 5:1) to give a light yellow solid. Yield: $1.75 \mathrm{~g}$ (85\%). ${ }^{1} \mathrm{H}$ NMR $\left(300 \mathrm{MHz}, \mathrm{CDCl}_{3}\right): \delta(\mathrm{ppm}) 7.39(\mathrm{~d}, J=9.0 \mathrm{~Hz}$, $2 \mathrm{H}), 6.80(\mathrm{~d}, J=9.0 \mathrm{~Hz}, 2 \mathrm{H}), 3.92(\mathrm{t}, J=6.6 \mathrm{~Hz}, 2 \mathrm{H}), 3.62(\mathrm{t}, J$ $=6.6 \mathrm{~Hz}, 2 \mathrm{H}), 2.97(\mathrm{~s}, 1 \mathrm{H}), 1.80-1.70(\mathrm{~m}, 2 \mathrm{H}), 1.57-1.50(\mathrm{~m}$, $2 \mathrm{H}), 1.42-1.29(\mathrm{~m}, 12 \mathrm{H})$.

1-\{[4-(10-Hydroxydecyloxy)phenyl]ethynyl\}-2,5-dimethoxy-4-[2(4-pyridyl)ethenyl]benzene (9). A solution of $\mathbf{5}(1.0 \mathrm{~g}, 2.72 \mathrm{mmol})$, 8 (0.78 g, $2.85 \mathrm{mmol})$, and $\mathrm{PPh}_{3}(14.1 \mathrm{mg}, 0.054 \mathrm{mmol})$ in $80 \mathrm{~mL}$ of dry $\mathrm{Et}_{3} \mathrm{~N} / \mathrm{THF}(1: 1)$ was degassed with nitrogen for $5 \mathrm{~min}$. Then, the solution was added with $\mathrm{CuI}(10.3 \mathrm{mg}, 0.054 \mathrm{mmol})$ and $\mathrm{Pd}\left(\mathrm{PPh}_{3}\right)_{2} \mathrm{Cl}_{2}(19.1 \mathrm{mg}, 0.027 \mathrm{mmol})$ at room temperature, and it was stirred to react at $50{ }^{\circ} \mathrm{C}$ overnight. The mixture was filtered, and the solvent was removed in vacuum. The crude mixture was extracted using dichloromethane, and the extract was washed with water, dried over $\mathrm{Na}_{2} \mathrm{SO}_{4}$, and then evaporated. After that, the crude product was purified by column chromatography (aluminum oxide, dichloromethane/acetone 40:1) to give a yellow solid. Yield: $1.28 \mathrm{~g}$ (92\%). ${ }^{1} \mathrm{H} \mathrm{NMR}\left(300 \mathrm{MHz}, \mathrm{CDCl}_{3}\right): \delta(\mathrm{ppm}) 8.56(\mathrm{~d}, J=4.5 \mathrm{~Hz}$, $2 \mathrm{H}), 7.66(\mathrm{~d}, J=16.5 \mathrm{~Hz}, 1 \mathrm{H}), 7.50(\mathrm{~d}, J=9.0 \mathrm{~Hz}, 2 \mathrm{H}), 7.39(\mathrm{~d}$, $J=4.5 \mathrm{~Hz}, 2 \mathrm{H}), 7.11(\mathrm{~s}, 1 \mathrm{H}), 7.04(\mathrm{~d}, J=16.5 \mathrm{~Hz}, 1 \mathrm{H}), 7.04(\mathrm{~s}$, $1 \mathrm{H}), 6.87(\mathrm{~d}, J=9.0 \mathrm{~Hz}, 2 \mathrm{H}), 3.99(\mathrm{t}, J=6.6 \mathrm{~Hz}, 2 \mathrm{H}), 3.97(\mathrm{~s}$, $3 \mathrm{H}), 3.89(\mathrm{~s}, 3 \mathrm{H}), 3.62(\mathrm{t}, J=6.6 \mathrm{~Hz}, 2 \mathrm{H}), 1.81-1.72(\mathrm{~m}, 2 \mathrm{H})$, $1.57-1.51(\mathrm{~m}, 2 \mathrm{H}), 1.41-1.30(\mathrm{~m}, 12 \mathrm{H})$. 
1-\{[4-(10-Methacryloyloxydecyloxy)phenyl]ethynyl\}-2,5-dimethoxy4-[2-(4-pyridyl)ethenyl]benzene, PBB (M1). To a Schlenk tube, compound 9 (1.0 g, $1.95 \mathrm{mmol})$, vinyl methacrylate $(0.55 \mathrm{~g}, 4.88$ mmol), 1,3-dichloro-1,1,3,3-tetrabutyldistannoxane (43.12 mg, 0.078 $\mathrm{mmol}$ ), and 2,6-di-tert-butyl-4-methylphenol (25.78 mg, 0.117 $\mathrm{mmol})$ in dry THF $(2 \mathrm{~mL})$ were purged with nitrogen for $15 \mathrm{~min}$ at room temperature. The tube was sealed and heated with stirring at $50{ }^{\circ} \mathrm{C}$ for 2 days. After cooling to room temperature, the reaction mixture was extracted using dichloromethane, and the extract was washed with water, dried over $\mathrm{Na}_{2} \mathrm{SO}_{4}$, and then evaporated. The crude product was purified by column chromatography (aluminum oxide, $n$-hexane/dichloromethane 1:1) and then washed with hexane to give a light yellow solid. Yield: $0.97 \mathrm{~g}(85 \%)$. ${ }^{1} \mathrm{H}$ NMR $(300$ $\left.\mathrm{MHz}, \mathrm{CDCl}_{3}\right): \delta(\mathrm{ppm}) 8.57(\mathrm{~d}, J=4.5 \mathrm{~Hz}, 2 \mathrm{H}), 7.66(\mathrm{~d}, J=16.5$ $\mathrm{Hz}, 1 \mathrm{H}), 7.50(\mathrm{~d}, J=9.0 \mathrm{~Hz}, 2 \mathrm{H}), 7.39$ (d, $J=4.5 \mathrm{~Hz}, 2 \mathrm{H}), 7.11$ $(\mathrm{s}, 1 \mathrm{H}), 7.04(\mathrm{~d}, J=16.5 \mathrm{~Hz}, 1 \mathrm{H}), 7.04(\mathrm{~s}, 1 \mathrm{H}), 6.87(\mathrm{~d}, J=9.0$ $\mathrm{Hz}, 2 \mathrm{H}), 6.10(\mathrm{~s}, 1 \mathrm{H}), 5.55(\mathrm{~s}, 1 \mathrm{H}), 4.14(\mathrm{t}, J=6.6 \mathrm{~Hz}, 2 \mathrm{H}), 3.97$ $(\mathrm{t}, J=6.6 \mathrm{~Hz}, 2 \mathrm{H}), 3.96(\mathrm{~s}, 3 \mathrm{H}), 3.89(\mathrm{~s}, 3 \mathrm{H}), 3.62(\mathrm{t}, J=6.6 \mathrm{~Hz}$, $2 \mathrm{H}), 1.95(\mathrm{~s}, 3 \mathrm{H}), 1.81-1.75(\mathrm{~m}, 2 \mathrm{H}), 1.58-1.53(\mathrm{~m}, 2 \mathrm{H})$, 1.42-1.30 (m, 12H). HRMS (EI): calcd for $\mathrm{C}_{37} \mathrm{H}_{43} \mathrm{NO}_{5}, 581.3141$; found 581.3146. Anal. Calcd for $\mathrm{C}_{37} \mathrm{H}_{43} \mathrm{NO}_{5}$ : C, 76.39; $\mathrm{H}, 7.45$; N, 2.41. Found: C, 76.15; H, 7.37; N, 2.44.

General Procedure for the Syntheses of Homopolymers and Copolymers (P1-P5). All polymerization procedures were carried out according to the free radical polymerization described by the following steps. To a Schlenk tube, $1.5 \mathrm{~g}$ of monomers M1, M2, or the mixture of $\mathbf{M} 1$ and $\mathbf{M} 2$ was dissolved in dry THF $(7.5 \mathrm{~mL})$ with $20 \mathrm{wt} \%$ of monomer concentration and AIBN ( 2 mol \% of total monomer concentration) as an initiator. The solution was degassed by three freeze-pump-thaw cycles and then sealed off. The reaction mixture was stirred and heated at $60{ }^{\circ} \mathrm{C}$ for $24 \mathrm{~h}$. After polymerization, the polymer was precipitated into diethyl ether. Then, the precipitated polymer was collected, washed with diethyl ether, and dried under high vacuum.

P1 (HPBB). ${ }^{1} \mathrm{H}$ NMR (300 MHz, DMSO- $\left.d_{6}\right): \delta(\mathrm{ppm}) 8.44(\mathrm{br}$, 2H), 7.53-6.77 (br, 10H), $3.80(\mathrm{br}, 10 \mathrm{H}), 1.66-1.24(\mathrm{br}, 21 \mathrm{H})$.

P2 (PBB-CAZ ${ }_{1}$ ). ${ }^{1} \mathrm{H}$ NMR (300 MHz, DMSO- $\left.d_{6}\right): \delta(\mathrm{ppm}) 8.46$ (br, 2H), 7.97-6.75 (br, 18H), 3.88 (br, 14H), 1.43-1.08 (br, 26H).

P3 (PBB-CAZ ${ }_{5}$ ). ${ }^{1} \mathrm{H}$ NMR (300 MHz, DMSO- $\left.d_{6}\right): \delta$ (ppm) 8.48 (br, 2H), 7.92-6.76 (br, 50H), 4.33-3.83 (br, 30H), 1.43-0.06 (br, 46H).

P4 (PBB-CAZ $)$ ). ${ }^{1} \mathrm{H}$ NMR (300 MHz, DMSO- $\left.d_{6}\right): \delta$ (ppm) 8.48 (br, 2H), 7.88-6.76 (br, 80H), 4.34-3.83 (br, 45H), 1.43-0.16 (br, 65H).

P5 (HCAZ). ${ }^{1} \mathrm{H}$ NMR (300 MHz, DMSO- $\left.d_{6}\right): \delta(\mathrm{ppm}) 7.89(\mathrm{br}$, 2H), 7.32-7.00 (br, 6H), 4.34-3.94 (br, 4H), 0.99-0.15 (br, 5H).

Sample Preparation of Supramolecular Side-Chain Copolymers (i.e., H-Bonded Side-Chain Dendritic Complexes). Hbonded side-chain dendritic complexes were made of appropriate (fully H-bonded) molar ratios of $\mathrm{H}$-acceptor copolymers (P3 and P4) and dendritic H-donors (G1COOH-G3COOH) in THF solutions, and then the solvent was removed by slow evaporation and followed by drying under vacuum at $50{ }^{\circ} \mathrm{C}$.

\section{Results and Discussion}

Syntheses and Characterization of Polymers. The synthetic routes of monomer PBB (M1) and polymers P1-P5 are shown in Scheme 1. The starting material 1 (i.e., 4-iodo-2,5dimethoxybenzaldehyde) was synthesized by following a reported procedure ${ }^{42}$ via iodination of 2,5-dimethoxybenzaldehyde with iodine and silver nitrate in the presence of methanol. The aldehyde group of compound $\mathbf{1}$ was further reduced to a benzyl alcohol and then was transformed into a benzyl chloride group with hydrochloric acid in the presence of 1,4-dioxane to give compound 3, which was converted to the corresponding phosphonate ester $\mathbf{4}$ by Michaelis-Arbuzov reaction under the triethyl phosphite treatment with a yield of $90 \% .{ }^{43}$ Compound 5 was prepared by means of Horner-Wadsworth-Emmons (HWE) olefination reaction between compound $\mathbf{4}$ and pyridine4-carboxaldehyde using potassium tert-butoxide as a base in
Table 1. Composition, Yields, Molecular Weights, and Degradation Temperatures of Polymers P1-P5

\begin{tabular}{|c|c|c|c|c|c|c|}
\hline \multirow[b]{2}{*}{ polymer } & \multicolumn{2}{|c|}{ molar ratio } & \multirow[b]{2}{*}{$\begin{array}{c}\text { yield } \\
(\%)\end{array}$} & \multirow[b]{2}{*}{$\underset{(\mathrm{g} / \mathrm{mol})^{b}}{M_{\mathrm{W}}}$} & \multirow[b]{2}{*}{$\begin{array}{c}\text { PDI } \\
\left(M_{\mathrm{w}} / M_{\mathrm{n}}\right)^{b}\end{array}$} & \multirow[b]{2}{*}{$\begin{array}{c}T_{\mathrm{d}} \\
\left({ }^{\circ} \mathrm{C}\right)^{c}\end{array}$} \\
\hline & $\begin{array}{c}\text { feed } \\
\text { monomer } \\
(\mathbf{P B B} / \mathbf{C A Z})\end{array}$ & $\begin{array}{c}\text { polymers } \\
(x / y)^{a}\end{array}$ & & & & \\
\hline P1 (HPBB) & $1 / 0$ & $1 / 0$ & 73 & 14400 & 1.72 & 357 \\
\hline P2 (PBB-CAZ 1 ) & $1 / 1$ & $1 / 1$ & 88 & 38100 & 3.24 & 323 \\
\hline P3 (PBB-CAZ & $1 / 5$ & $1 / 5$ & 85 & 45600 & 2.99 & 305 \\
\hline P4 (PBB-CAZ $)$ & $1 / 10$ & $1 / 9$ & 81 & 53100 & 3.69 & 300 \\
\hline P5 (HCAZ) & $0 / 1$ & $0 / 1$ & 75 & 47800 & 3.65 & 276 \\
\hline
\end{tabular}

${ }^{a}$ Determined by ${ }^{1} \mathrm{H}$ NMR spectra. ${ }^{b}$ Weight-average molecular weight $\left(M_{\mathrm{W}}\right)$ and polydispersity index (PDI) determined by GPC in THF using polystyrene as a standard. ${ }^{c}$ Temperature $\left({ }^{\circ} \mathrm{C}\right)$ at $5 \%$ weight loss measured by TGA at a heating rate of $20{ }^{\circ} \mathrm{C} \mathrm{min}-1$ under nitrogen.

THF to give $60 \%$ yield. $^{44}$ Compound $\mathbf{6}$ in $80 \%$ yield was obtained by reaction of 4-bromophenol with 10-bromodecanol under Williamson etherification condition $\left(\mathrm{K}_{2} \mathrm{CO}_{3}\right.$ /acetone $)$. The latter Sonogashira (Pd-catalyzed) coupling reaction of compound 6 with 2-methyl-3-butyn-2-ol afforded compound 7 in the presence of a catalytic amount $(1 \mathrm{~mol} \%)$ of $\mathrm{Pd}\left(\mathrm{PPh}_{3}\right)_{2} \mathrm{Cl}_{2}$ in $\mathrm{Et}_{3} \mathrm{~N}$ with a yield of $78 \%,{ }^{45}$ which was then deprotected with $\mathrm{KOH} / 1,4-$ dioxane to acquire compound $\mathbf{8}$ in $85 \%$ yield. Subsequently, the three-conjugated rings of compound $\mathbf{9}$ with a yield of $92 \%$ was prepared through a second Sonogashira coupling reaction between compounds 8 and $\mathbf{5}$ in $\mathrm{Et}_{3} \mathrm{~N} / \mathrm{THF}$ (1:1). Finally, monomer PBB (M1) with a high yield of $85 \%$ was obtained by transesterification reaction ${ }^{46}$ between compound 9 and an excess amount (2.5 equiv) of vinyl methacrylate in the presence of a higher concentration of 1,3-dichloro-1,1,3,3tetrabutyldistannoxane as a catalyst and 2,6-di-tert-butyl-4methylphenol as an inhibitor in THF. The yield is much better than that reported ${ }^{47}$ by our previous esterification reaction. The final chemical structure of monomer PBB (M1) was confirmed by ${ }^{1} \mathrm{H}$ NMR spectroscopy, HRMS, and elemental analysis (see Experimental Section and Supporting Information).

The polymerization reactions with good yields (ranging $73-88 \%$ ) were carried out in THF at $60{ }^{\circ} \mathrm{C}$ through free radical polymerization in the presence of azobis(isobutyronitrile) (AIBN) as an initiator. The feeding ratios of monomers PBB (M1) to CAZ (M2) were 1:0, 1:1, 1:5, 1:10, and 0:1, respectively, to acquire $\mathrm{H}$-acceptor polymers P1-P5. The chemical structures of polymers P1-P5 in DMSO- $d_{6}$ were verified by ${ }^{1} \mathrm{H}$ NMR spectroscopy in comparison with those of their monomers PBB (M1) and CAZ (M2) (see Supporting Information). In the ${ }^{1} \mathrm{H}$ NMR spectra of polymers, the disappearance of proton peaks in the region of vinyl (methacrylate) groups with chemical shifts at 5.4-6.1 ppm indicated that all monomers were reacted. The copolymer compositions were estimated by comparing the relative integration areas of the peaks at $8.5 \mathrm{ppm}$ (corresponding to two protons of $\alpha$-pyridyl groups in PBB) and 6.7-7.9 ppm (corresponding to the other overlapped aromatic protons of $\mathbf{P B B}$ and $\mathbf{C A Z}$ units), respectively. Regarding the compositions of copolymers $\mathbf{P 2}-\mathbf{P 4}$, the actual compositions of $\mathbf{P 2}$ and $\mathbf{P 3}$ are very close to the feeding ratios of monomers, except that $\mathbf{P 4}$ has a slightly lower molar ratio than that of feeding. All polymers are soluble in common organic solvents, such as THF, DMSO, and DMF. The weightaverage molecular weights $\left(M_{\mathrm{w}}\right)$ and polydispersity indexes (PDI) of polymers P1-P5, determined by gel permeation chromatography (GPC) with THF as the eluting solvent and polystyrene as standards, are in the range $14400-53100 \mathrm{~g} / \mathrm{mol}$ and 1.72-3.69, respectively. The compositions (input and output molar ratio), molecular weights $\left(M_{\mathrm{w}}\right)$, PDI values, and yields of polymers P1-P5 are summarized in Table 1.

The existence of hydrogen bonds in the H-bonded complexes can be confirmed by FTIR spectroscopy. Therefore, the IR spectra (at room temperature) of $\mathrm{H}$-acceptor polymer P3, 


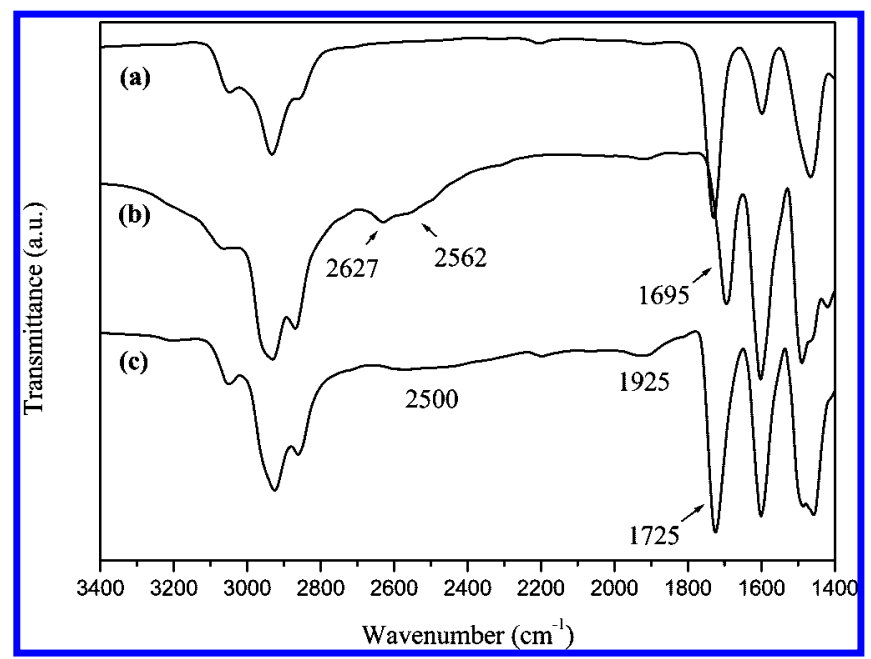

Figure 3. FTIR spectra of (a) H-acceptor polymer P3 (PBB-CAZ $)$, (b) dendritic H-donor G1COOH, and (c) H-bonded side-chain dendritic complexes P3/G1COOH at room temperature.

H-donor G1COOH, and H-bonded side-chain dendritic complexes (side-chain copolymers with pendent dendrimers) P3/ G1COOH shown in Figure 3 are compared to analyze the formation of hydrogen bonds between $\mathrm{H}$-acceptor polymer P3 and $\mathrm{H}$-donor dendrimer $\mathbf{G 1 C O O H}$. In contrast to the $\mathrm{O}-\mathrm{H}$ bands of pure $\mathrm{H}$-donor (H-bonded dendritic dimer) $\mathbf{G 1 C O O H}$ at 2627 and $2562 \mathrm{~cm}^{-1}$, the weaker $\mathrm{O}-\mathrm{H}$ bands observed at 1925 and $2500 \mathrm{~cm}^{-1}$ in the H-bonded side-chain dendritic complex P3/G1COOH are indicative of stronger hydrogen bonding between the pyridyl groups of polymer $\mathbf{P 3}$ and the carboxylic acid of G1COOH in the H-bonded complex. On the other hand, a stretching vibration of $\mathrm{C}=\mathrm{O}$ at $1695 \mathrm{~cm}^{-1}$ in pure G1COOH is shifted toward higher wavenumber and overlapped with the band of the ester carbonyl groups at 1725 $\mathrm{cm}^{-1}$ in the H-bonded dendritic complex P3/G1COOH, which shows that the carbonyl group was in a less associated state than that in the pure $\mathrm{H}$-bonded dimer state of $\mathrm{H}$-donor G1COOH. These results suggest that hydrogen bonds were formed between P3 and G1COOH in the solid state of the H-bonded dendritic complex P3/G1COOH. The other H-bonded complexes discussed in this study should have similar consequences as the demonstrated H-bonded complexes. ${ }^{48}$

Thermal Properties. The thermal stabilities of polymers P1-P5 were evaluated by thermogravimetric analyses (TGA), and their corresponding data are also summarized in Table 1. The TGA analyses indicate that the degradation temperatures $\left(T_{\mathrm{d}}\right)$ of polymers with $5 \%$ weight loss (under nitrogen) are between 276 and $357^{\circ} \mathrm{C}$, and $T_{\mathrm{d}}$ values decrease with increasing the molar ratio of monomer CAZ (M2) monotonically. Hence, homopolymers P1 (HPBB) and P5 (HCAZ) have the highest and lowest thermal stabilities, respectively, which means that the carbazole unit of monomer CAZ (M2) is less stable than the light-emitting unit of PBB (M1) in polymers P1-P5 (see Supporting Information).

The phase transition temperatures of polymers P1-P5 and $\mathrm{H}$-bonded side-chain dendritic complexes containing $\mathrm{H}$-acceptor polymers P2 (PBB-CAZ $)$, P3 (PBB-CAZ $)$, and P4 (PBBCAZ9), which were determined by differential scanning calorimetry (DSC) under nitrogen, are summarized in Table 2. Polymers P1 $-\mathbf{P 5}$ only show glass transition temperatures $\left(T_{\mathrm{g}} \mathrm{s}\right)$, but without any melting and crystallization peaks. The $T_{\mathrm{g}}$ values of polymers P1-P5 (ranging $63-142{ }^{\circ} \mathrm{C}$ ) gradually increase as the CAZ (M2) molar ratio increases. Hence, higher $T_{\mathrm{g}}$ values of copolymers with higher $\mathbf{C A Z}$ contents can be originated from the contribution of the bulky carbazole pendent groups, where
Table 2. Glass Transition Temperatures of Polymers P1-P5 and H-Bonded Side-Chain Dendritic Complexes Containing H-Acceptor Polymers P2-P4

\begin{tabular}{|c|c|c|c|}
\hline $\begin{array}{c}\text { polymer or } \\
\text { H-bonded complex }\end{array}$ & $T_{\mathrm{g}}\left({ }^{\circ} \mathrm{C}\right)$ & $\begin{array}{c}\text { polymer or } \\
\text { H-bonded complex }\end{array}$ & $T_{\mathrm{g}}\left({ }^{\circ} \mathrm{C}\right)$ \\
\hline P1 (HPBB) & 63 & P2/G3COOH & $-^{a}$ \\
\hline P2 $($ PBB-CAZ 1$)$ & 88 & P3/G1COOH & 81 \\
\hline P3 $\left(\right.$ PBB-CAZ $\left.{ }_{5}\right)$ & 117 & P3/G2COOH & 86 \\
\hline P4 (PBB-CAZ 9$)$ & 125 & P3/G3COOH & 83 \\
\hline P5 (HCAZ) & 142 & P4/G1COOH & 88 \\
\hline P2/G1COOH & 60 & P4/G2COOH & 99 \\
\hline P2/G2COOH & 68 & P4/G3COOH & 89 \\
\hline
\end{tabular}

${ }^{a}$ Omitted due to the possible unstabilized $\mathrm{H}$-bonded structures originated from the highest steric hindrance between the highest generation of dendrimer $\mathbf{G 3 C O O H}$ and the denser $\mathrm{H}$-acceptor units in $\mathbf{P 2}$.

the mobility of polymeric chains are restricted due to the steric hindrance and rigidity of carbazole units.

During the heating run of polarizing optical microscopy (POM) study in the glassy state of polymers, homopolymer P1 (HPBB) exhibited weak birefringent behavior (up to the clearing point of $125^{\circ} \mathrm{C}$ ) corresponding to a characteristic mesophase at $90{ }^{\circ} \mathrm{C}$ (see Supporting Information), which was further confirmed by powder X-ray diffraction (XRD). The diffraction pattern has two diffuse halos in the small- and wide-angle regions, respectively, indicating the absence of any positional order as a smectic or highly ordered phase. ${ }^{49}$ Hence, these results suggest that the mesogenic homopolymer P1 showed the nematic phase [glassy $\left(64^{\circ} \mathrm{C}\right)$ nematic $\left(125^{\circ} \mathrm{C}\right)$ isotropic]. However, only homopolymer $\mathbf{P 1}$ formed the nematic phase, and the other polymers P2-P5 do not have any mesogenic properties, which is probable that the incorporation of the bulky carbazole groups into the copolymer system will disturb the self-assembly of rigid rods in PBB units and thus to prohibit from their mesogenic behavior.

To elucidate the H-bonding effect on the thermal properties of supramolecular side-chain dendritic complexes, OXD dendritic $\mathrm{H}$-donors (bearing benzoic acids) were introduced to be H-bonded with light-emitting $\mathrm{H}$-acceptor copolymers P2 (PBBCAZ 1 ), P3 (PBB-CAZ $)$, and P4 (PBB-CAZ $)$ ), where P2/ G3COOH is omitted due to the possible unstabilized H-bonded structures originated from the highest steric hindrance between the highest generation of dendrimer $\mathbf{G 3 C O O H}$ and the denser $\mathrm{H}$-acceptor units in P2. As shown in Table 2, both series of $\mathrm{H}$-bonded side-chain dendritic complexes containing $\mathrm{H}$-acceptor polymers P3 and P4 show only a single $T_{\mathrm{g}}$, which suggests good miscibilities between OXD dendritic H-donors (i.e., G1COOH-G3COOH) and H-acceptor polymers (i.e., P3 and P4). Besides, since no melting and crystallization were observed in the DSC measurements, it suggests that these H-bonded dendritic complexes possess amorphous characteristics. Moreover, neither phase separation nor mesogenic properties were observed in the POM measurements. However, the $T_{\mathrm{g}}$ values of supramolecular side-chain dendritic complexes (containing P3 and P4) are notably lower than those of their $\mathrm{H}$-acceptor copolymers (i.e., P3 and P4). This result may be explained by that the free volumes of the H-bonded side-chain dendritic complexes were enhanced by the bulky dendritic structures of the OXD H-donors.

In comparison with different generations of $\mathrm{H}$-bonded sidechain dendritic complexes containing P3 and P4 (i.e., P3/ G1COOH-G3COOH and P4/G1COOH-G3COOH), both series of $T_{\mathrm{g}}$ values increase initially with enlarging the generation number of the OXD dendron from $\mathrm{G} 1$ to $\mathrm{G} 2$, reaching the highest values at dendrimer G2 (i.e., P3/G2COOH and P4/ G2COOH). With the further increase of the generation number to dendrimer $\mathrm{G} 3$, both series of $T_{\mathrm{g}}$ values begin to decrease. The initial increase in the $T_{\mathrm{g}}$ value is probably due to the increase of the molecular weight in a larger dendron (from G1 to G2), 
Table 3. Absorption and PL Emission Spectral Data of H-Acceptor Monomer M1 (PBB) and Polymers P1-P5 in THF Solutions and Solid Films

\begin{tabular}{lllll}
\hline \multicolumn{1}{c}{ polymer } & \multicolumn{1}{c}{$\lambda_{\text {abs,sol }}{ }^{a}(\mathrm{~nm})$} & $\begin{array}{c}\lambda_{\mathrm{PL}, \mathrm{sol}}{ }^{a, b} \\
(\mathrm{~nm})\end{array}$ & $\begin{array}{c}\lambda_{\mathrm{PL}, \mathrm{film}}{ }^{b} \\
(\mathrm{~nm})\end{array}$ & $\Phi_{\mathrm{PL}, \mathrm{sol}}{ }^{b, c}$ \\
\hline M1 (PBB) & 320,385 & 445 & 495 & 0.52 \\
P1 (HPBB) & 320,385 & 449 & 496 & 0.49 \\
P2 (PBB-CAZ & $294,320,342,385$ & 447 & 487 & 0.68 \\
P3 (PBB-CAZ) & $294,328,342,385$ & 445 & 469 & 0.83 \\
P4 (PBB-CAZ) & $294,328,342,385$ & 444 & 466 & 0.94 \\
P5 (HCAZ) & $294,328,343$ & 348,364 & 352,367 &
\end{tabular}

${ }^{a}$ Measured in dilute THF solutions. ${ }^{b}$ Excited at the maximum absorption of PBB units. ${ }^{c}$ Solution fluorescence quantum efficiencies were measured in THF, relative to 9,10 -diphenylanthracene $\left(\Phi_{\mathrm{PL}}=0.90\right)$.

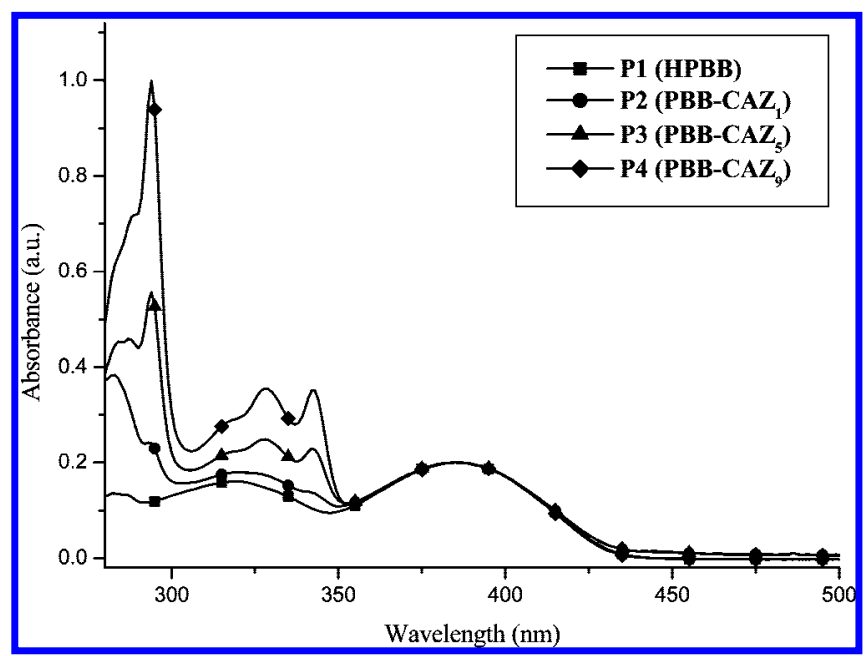

Figure 4. Absorption spectra of $\mathrm{H}$-acceptor polymers $\mathbf{P 1}-\mathbf{P 4}$ in $\mathrm{THF}$ solutions, normalized at the maximum absorption peak of the lightemitting PBB segments at $385 \mathrm{~nm}$.

which is similar to the phenomena observed in our previous study of H-bonded dendrimers. ${ }^{37}$ However, the further decrease in the $T_{\mathrm{g}}$ value of the highest generation number $(\mathrm{G} 3)$ is due to the free volume effect (increasing with enlarging the size of the dendritic OXD wedges so as to decrease the adjacent polymeric chain interactions) being more dominant than the molecular weight effect, which was also described in our previous polyfluorene polymers containing OXD dendritic pendants. ${ }^{50}$ Therefore, the competition between the free volume effect and the molecular weight effect influenced the $T_{\mathrm{g}}$ values of $\mathrm{H}$-bonded side-chain dendritic complexes containing $\mathbf{P 3}$ and resulted in the following order: P3/G2COOH $>$ P3/G3COOH $>$ P3/G1COOH. A similar tendency was also observed in analogous H-bonded dendritic complexes containing P4. However, there were some possibilities for unstabilized H-bonded structures of complexes made from the highest generation of dendrimer $\mathbf{G 3 C O O H}$ and the denser $\mathrm{H}$-acceptor units in M1 and $\mathbf{P 2}$ due to the steric hindrance within the higher generations of dendrimers and hence to induce the incomplete H-bonded complexes. Therefore, the decrease of $T_{\mathrm{g}}$ values in the complexes might be also attributed to the plasticizing effect of the non-H-bonded dendrimers, which were homogeneously dispersed in the complexes.

Optical Properties. The absorption and photoluminescence (PL) spectra of H-acceptor monomer M1 (PBB) and polymers P1-P5 were measured in both solution and solid states, and their photophysical properties are summarized in Table 3. As shown in Figure 4, the absorption intensities of copolymers P2-P4 at 294, 328, and $342 \mathrm{~nm}$ (in THF solutions) increase dramatically by raising the $\mathbf{C A Z}$ content, which are attributed to the absorption bands of the $\mathbf{C A Z}$ moieties. The additional absorption bands of polymers P1-P4 at ca. 320 and $385 \mathrm{~nm}$

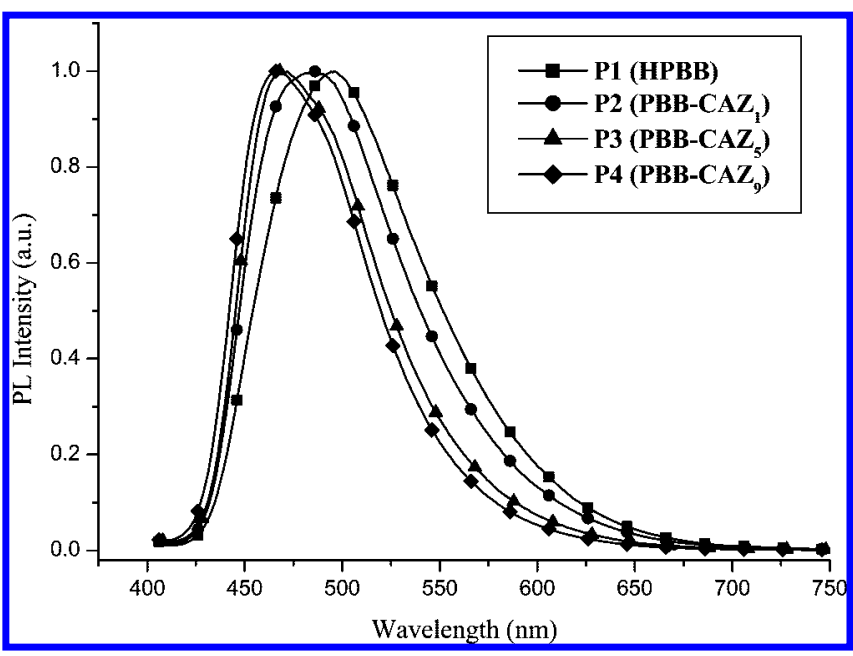

Figure 5. Normalized PL spectra of H-acceptor polymers P1-P4 excited at the maximum absorption $(397 \mathrm{~nm})$ of the light-emitting PBB segments in solid films.

are assigned to the light-emitting PBB segments of the Hacceptor moieties. The copolymers do not demonstrate any new (or shifted) bands in the absorption spectra, indicating no interaction between the $\mathbf{C A Z}$ and PBB moieties in the ground state. The absorption spectra of the polymers in solid films are similar except for 5-7 $\mathrm{nm}$ of red shifts in contrast to those in THF solutions (see Supporting Information). The PL emission spectra of polymers $\mathbf{P 1}-\mathbf{P 4}$ in solid films show 22-47 nm of significant red shifts, i.e., P1 $(47 \mathrm{~nm})>\mathbf{P 2}(40 \mathrm{~nm})>\mathbf{P 3}(24$ $\mathrm{nm})>\mathbf{P} 4(22 \mathrm{~nm})$, in comparison with their corresponding dilute solutions (see Table 3), which is due to the formation of $\pi-\pi$ stacking and molecular aggregation in solid state. Furthermore, compared with copolymers P2-P4 in solid films as shown in Figure 5, homopolymer P1 exhibits the largest red shift, i.e., $47 \mathrm{~nm}$, in PL spectra. With the increase of $\mathbf{C A Z}$ contents in copolymers P2-P4, the PL peaks are blue-shifted from 487 $\mathrm{nm}$ in $\mathbf{P 2}$ to $466 \mathrm{~nm}$ in $\mathbf{P 4}$. This result clearly indicates that the dilution effect by the $\mathbf{C A Z}$ moieties can be incorporated into the copolymers to suppress the intermolecular $\pi-\pi$ stacking and the aggregation of the light-emitting PBB units in polymers and thus to reduce the red shifts (by aggregation) in the PL emission spectra. As listed in Table 3, the PL quantum yields $\left(\Phi_{\mathrm{PL}}\right)$ of polymers $\mathbf{P 1}-\mathbf{P 4}$ in solutions were in the order of P1 $<\mathbf{P 2}<\mathbf{P 3}<\mathbf{P 4}$, where $\mathbf{P 4}$ has the largest quantum yield $\left(\Phi_{\mathrm{PL}}\right.$ $=0.94$ ) due to the highest content of CAZ moieties. This consequence indicates that the dilution effect of $\mathbf{C A Z}$ units in the copolymers will reduce the aggregation and self-quenching of the PBB segments to acquire higher PL quantum yields.

In order to investigate the generation effect of OXD dendrons on the absorption spectra of $\mathrm{H}$-bonded side-chain dendritic complexes (in solid films), the absorption spectra of model compound 1 (containing an OXD unit, which is illustrated in the Supporting Information) in THF solution and $\mathrm{H}$-acceptor polymer $\mathbf{P 3}$ in solid state are compared. ${ }^{37}$ As shown in the absorption spectra of Figure 6, the maximum absorption wavelength $\lambda_{\text {max,abs }}$ of model compound $\mathbf{1}$ in THF solution is ca. $305 \mathrm{~nm}$ (from OXD units) and that of H-acceptor polymer $\mathbf{P 3}$ in solid state is ca. $296 \mathrm{~nm}$ (from CAZ units). Nevertheless, the major absorption bands of $\mathrm{H}$-bonded side-chain dendritic complexes containing $\mathbf{P 3}$ in solid films are dominated at ca. $296 \mathrm{~nm}$ (from CAZ units) with a shoulder at ca. $315 \mathrm{~nm}$ (from OXD units), which are originated from the combined absorption band of the OXD and CAZ moieties. The longer absorption band at ca. $397 \mathrm{~nm}$ is attributed to the characteristic absorption of the light-emitting PBB units. By increasing the generation number of the dendritic $\mathrm{H}$-donors in the $\mathrm{H}$-bonded side- 


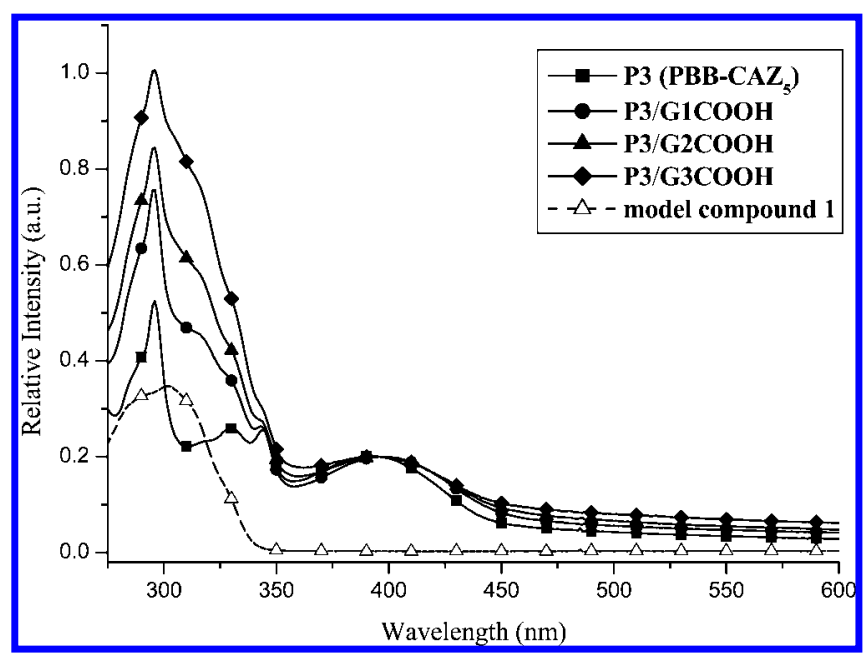

Figure 6. Absorption spectra of $\mathrm{H}$-acceptor polymer $\mathbf{P 3}$ and its $\mathrm{H}$-bonded side-chain dendritic complexes in solid films normalized at the maximum absorption (397 nm) of the light-emitting PBB cores along with model compound $\mathbf{1}$ (containing an OXD unit with the maximum absorption around $305 \mathrm{~nm}$ in THF solution).

Table 4. Photophysical Properties of H-Bonded Side-Chain Dendritic Complexes Containing H-Acceptor Monomer M1 (PBB) and Polymers P2-P4

\begin{tabular}{cccc}
\hline H-bonded complex & $\lambda_{\mathrm{PL}, \mathrm{film}}(\mathrm{nm})$ & $\Delta \lambda_{\mathrm{PL}}{ }^{a}(\mathrm{~nm})$ & $\mathrm{RFI}^{b}$ \\
\hline M1/G1COOH & 561 & 66 & 0.93 \\
M1/G2COOH & 555 & 60 & 1.25 \\
M1/G3COOH & $-^{c}$ & $-^{c}$ & $-^{c}$ \\
P2/G1COOH & 547 & 49 & 0.91 \\
P2/G2COOH & 536 & 46 & 1.76 \\
P2/G3COOH & $-^{c}$ & $-^{c}$ & $-^{c}$ \\
P3/G1COOH & 530 & 61 & 1.56 \\
P3/G2COOH & 520 & 51 & 2.16 \\
P3/G3COOH & 509 & 40 & 3.14 \\
P4/G1COOH & 523 & 57 & 2.09 \\
P4/G2COOH & 512 & 46 & 2.44 \\
P4/G3COOH & 498 & 32 & 4.45 \\
\hline Difl
\end{tabular}

${ }^{a}$ Different degrees of red-shifted PL emissions between the H-boned side-chain dendrimers and their corresponding $\mathrm{H}$-acceptor copolymers. ${ }^{b}$

Relative fluorescent intensities (RFI) were calculated by the ratios of the core emission intensities excited at the absorption peaks of the OXD units $\left(305 \mathrm{~nm}\right.$ ) and the PBB cores (397 nm). ${ }^{c}$ Omitted due to the possible unstabilized $\mathrm{H}$-bonded structures originated from the highest steric hindrance between the highest generation of dendrimer $\mathbf{G 3 C O O H}$ and the denser $\mathrm{H}$-acceptor units in $\mathbf{M} \mathbf{1}$ and $\mathbf{P 2}$.

chain dendritic complexes, the intensity of the absorption band in the OXD moieties at ca. $305-315 \mathrm{~nm}$ is proportional to the generation number of the H-donor dendrimers. The photophysical properties of $\mathrm{H}$-bonded side-chain dendritic complexes containing $\mathrm{H}$-acceptor monomer M1 (PBB) and polymers $\mathbf{P 2}-\mathbf{P 4}$ in solid films are summarized in Table 4, where M1/ G3COOH and P2/G3COOH are omitted due to the possible unstabilized $\mathrm{H}$-bonded structures originated from the highest steric hindrance between the highest generation of dendrimer G3COOH and the denser H-acceptor units in M1 and P2. From the results of Table 4 , the least red-shifted PL emissions of $\Delta \lambda_{\mathrm{PL}}$ in P2/G1COOH and P2/G2COOH have the evidence of the possible unstabilized $\mathrm{H}$-bonded structures of complexes made from P2. Therefore, the possible unstabilized H-bonded structures of complexes made from $\mathbf{P} 2$ will be similar to those made from $\mathbf{P 1}$, in which the $\mathrm{H}$-bonded structures are possibly unsteady due to the steric hindrance between the denser $\mathrm{H}$-acceptor units in P1 (as well as P2) and the higher generation of dendrimers, especially for the highest generation of $\mathrm{H}$-bonded complexes containing G3COOH.

The photophysical properties of both series of H-bonded sidechain dendritic complexes containing $\mathrm{H}$-acceptor polymers P3

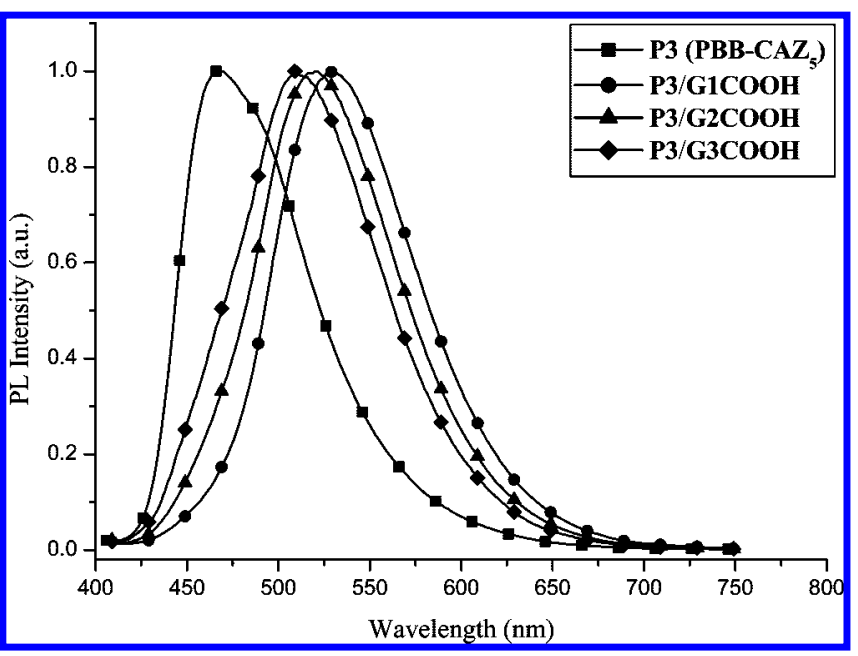

Figure 7. Normalized PL spectra of H-acceptor polymer P3 and its H-bonded side-chain dendritic complexes excited at the maximum absorption (397 nm) of the light-emitting PBB cores in solid films.

and P4 in solid films (see Table 4) are evaluated accordingly. Compared with $\mathrm{H}$-acceptor polymer $\mathbf{P 3}\left(\mathbf{P B B}-\mathbf{C A Z}_{5}\right)$ in Figure 7, the supramolecular side-chain dendritic complexes P3/ G1COOH-G3COOH (excited at the maximum absorption of the light-emitting PBB units) exhibit red-shifted PL emissions with $\lambda_{\max }$ values at 530,520 , and $509 \mathrm{~nm}$, respectively. This result is similar to our previous work ${ }^{51}$ that red shifts of PL emissions are expected in the H-bonded structures, where the nonphotoluminescent $\mathrm{H}$-donors bearing benzoic acids (as solid solvents) were $\mathrm{H}$-bonded to the photoluminescent $\mathrm{H}$-acceptors containing pyridyl groups. Therefore, analogous H-bonded sidechain dendritic complexes containing different generations of dendritic H-donors appeared to have different degrees of redshifted PL emissions in comparison with $\mathrm{H}$-acceptor polymer P3. The red shifts of PL emissions in H-bonded side-chain dendritic complexes P3/G1COOH-G3COOH are 61, 51, and $40 \mathrm{~nm}$, respectively, where the higher generation of the $\mathrm{H}$-bonded side-chain dendritic complex has a smaller red-shifted PL emission than the lower generation of the H-bonded sidechain dendritic complex. It clearly indicates that the larger dendritic wedges on the side chains have a larger site isolation or dendritic dilution effect than the smaller dendritic ones, so the higher generations of dendrimers efficiently minimize the interchain interaction and lower the aggregation extent between the light-emitting PBB units. The PL emission data of H-bonded dendritic dendrimers containing $\mathbf{P} \mathbf{4}$ are also summarized in Table 4, which demonstrate similar trends as those of $\mathrm{H}$-bonded dendritic dendrimers containing P3. However, in contrast to the same generation of OXD dendron, H-bonded dendritic complexes containing P4 have smaller degrees of red-shifted PL emissions than H-bonded dendritic complexes containing P3 (see Table 4). This might be due to the larger dilution effect of CAZ units in P4 (PBB-CAZ9) with higher CAZ contents than that in $\mathbf{P 3}(\mathbf{P B B}-\mathbf{C A Z}$ ), where a higher $\mathbf{C A Z}$ molar ratio of $\mathbf{P 4}$ reduces the interchain interaction between the light-emitting PBB units in these H-bonded side-chain dendritic complexes.

Because of the significant spectral overlap in the absorption spectrum of homopolymer P1 and the emission spectra of model compound 1 (containing an OXD unit) and homopolymer P5 (as shown in the Supporting Information), the energy transfer from the OXD dendritic wedges and $\mathbf{C A Z}$ pendant groups to the light-emitting PBB cores can be expected. This effect was also probed by photoluminescent excitation (PLE) and absorption spectra of $\mathrm{H}$-bonded side-chain dendritic complexes containing P4 (see Figure 8). Similar spectral features of PLE spectra appear to match those of their corresponding absorption 


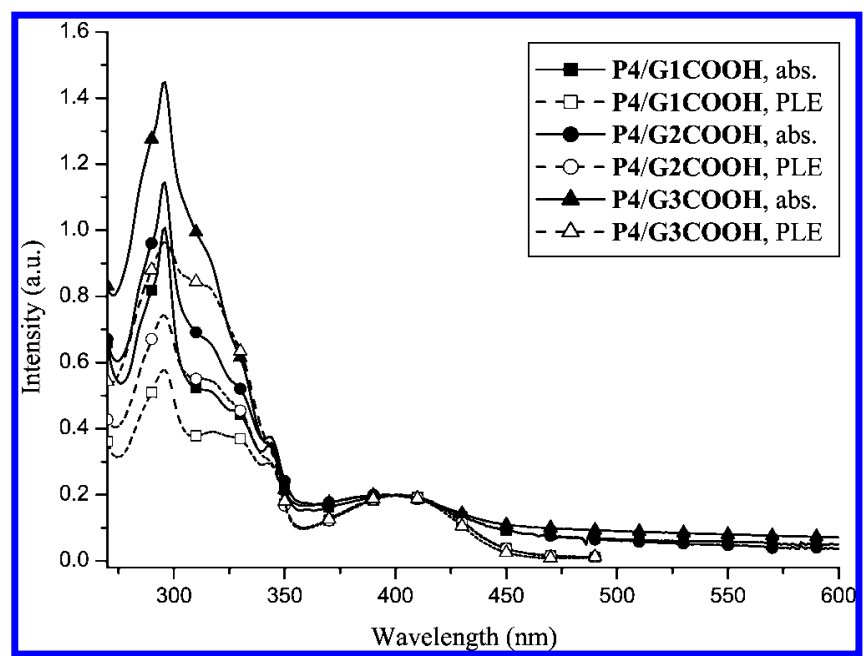

Figure 8. UV spectra and PLE spectra of $\mathrm{H}$-acceptor polymer $\mathbf{P 4}$ and its $\mathrm{H}$-bonded side-chain dendritic complexes in solid films normalized at the light-emitting PBB units $(397 \mathrm{~nm})$, where PLE spectra were monitored at the corresponding maximum PL emissions.

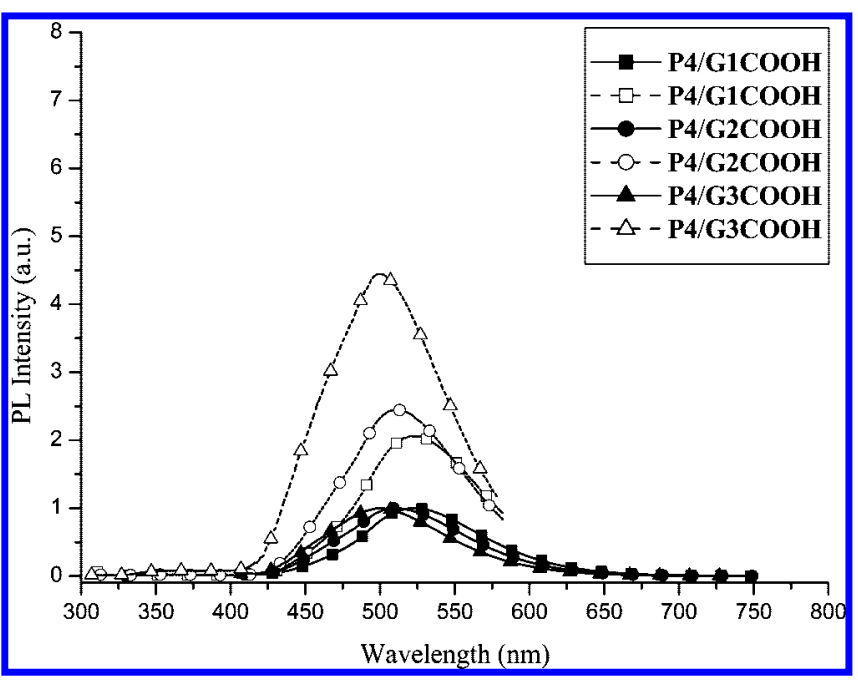

Figure 9. PL spectra of $\mathrm{H}$-acceptor polymer $\mathbf{P 4}$ and its H-bonded sidechain dendritic complexes in solid films, which were excited at the dendritic peripheral OXD units (at $305 \mathrm{~nm}$ for open symbols) and at the maximum absorption of the light-emitting PBB cores in H-bonded side-chain dendritic complexes containing dendritic H-donors (ca. 397 $\mathrm{nm}$ for solid symbols).

spectra, where PLE spectra were monitored at the corresponding maximum PL emission. This result indicates that the existing sites of CAZ pendent groups, peripheral OXD dendritic wedges, and light-emitting PBB cores (ca. 296, 305, and $397 \mathrm{~nm}$, respectively) in such supramolecular side-chain dendrimers provide the characteristics of light-harvesting capability, i.e., antenna effect. Since only the energy transfer of the dendritic OXD units in the H-bonded side-chain dendritic complexes is concerned, the excitation wavelength of $305 \mathrm{~nm}$ was chosen at the maximum absorption of the dendritic OXD units. As shown in Figure 9, different generations of $\mathrm{H}$-bonded dendritic complexes containing P4 (P4/G1COOH-G3COOH) have PL emissions at wavelengths of 545, 539, and $522 \mathrm{~nm}$, respectively. Upon excitation of the dendritic OXD units at $305 \mathrm{~nm}$, H-bonded dendritic complexes apparently generated identical predominant emission peaks as those excited at the maximum absorption of the PBB cores. Whereas, no major PL emission from OXD dendrons was detected, and thus an efficient energy transfer from the peripheral OXD units to the $\mathbf{P B B}$ cores is confirmed. Furthermore, the functionalized OXD dendritic units
Table 5. Electrochemical Properties of H-Acceptor Polymer P4 and Its H-Bonded Side-Chain Dendritic Complexes

\begin{tabular}{ccccc}
\hline $\begin{array}{c}\text { polymer or } \\
\text { H-bonded complex }\end{array}$ & \begin{tabular}{c} 
optical band $_{\mathrm{gap}^{a}(\mathrm{eV})}$ \\
\hline P4 (PBB-CAZ $)$
\end{tabular} & $\begin{array}{c}E_{\text {ox/onset }}{ }^{b} \\
(\mathrm{~V})\end{array}$ & $\begin{array}{c}\mathrm{HOMO} \\
(\mathrm{eV})\end{array}$ & $\begin{array}{c}\mathrm{LUMO}^{c} \\
(\mathrm{eV})\end{array}$ \\
P4/G1COOH & 2.79 & 1.24 & -5.64 & -2.85 \\
P4/G2COOH & 2.75 & 1.26 & -5.66 & -2.91 \\
P4/G3COOH & 2.77 & 1.27 & -5.67 & -2.91 \\
& 1.27 & -5.67 & -2.90
\end{tabular}

${ }^{a}$ Estimated from the onset wavelength of optical absorption in solid films. ${ }^{b}$ The onset oxidation potential vs SCE. ${ }^{c}$ LUMO values were estimated by the deduction of optical band gaps from HOMO values.

or the light-emitting PBB cores can be independently addressed by changing the excitation wavelengths in PL experiments. By excitation of the electron-transporting dendrons and the lightemitting cores selectively, it provides a window to study the photoinduced energy transfer between proton donors and acceptors.

In addition, different generations of $\mathbf{O X D}$ dendritic $\mathrm{H}$-donors were investigated to evaluate their antenna effect in the supramolecular side-chain dendrimers. Thus, the values of relative fluorescent intensities (RFI) in H-bonded side-chain dendritic complexes were calculated from the intensity ratios of their PBB core emissions by respective excitations at the maximum absorption peaks of the OXD dendrons (by the sensitized absorption at $305 \mathrm{~nm}$ and then energy transfer to PBB core emissions) and the maximum absorption peaks of the PBB cores (by the direct core absorption at $397 \mathrm{~nm}$ ), respectively. The RFI values of $\mathrm{H}$-bonded side-chain dendrimers containing $\mathrm{H}$-acceptor copolymer $\mathbf{P 4}$ and $\mathrm{H}$-donor dendrimers G1COOH to $\mathbf{G 3 C O O H}$ are $2.09,2.44$, and 4.45 , respectively (as shown in Figure 9 and Table 4), which indicates that the intensity of the sensitized emission (by the energy transfer from OXD dendritic absorption at $305 \mathrm{~nm}$ ) is even stronger than that of the direct PBB core emission (by the direct core absorption at $397 \mathrm{~nm}$ ) in the H-bonded side-chain dendrimers. Therefore, the RFI values are much enhanced in the higher generations of $\mathrm{H}$-bonded dendritic complexes (with the maximum values in both series of $\mathrm{H}$-bonded side-chain dendritic complexes bearing the highest generation of $\mathrm{H}$-donor dendrimer $\mathbf{G 3 C O O H}$ ), which is attributed to the higher absorptions by the larger numbers of OXD units in the higher generations of dendritic wedges as well as the further reduced aggregation of the light-emitting PBB cores by the more bulky sizes of dendrons in the higher generations of OXD H-donors.

Electrochemical Properties. The electrochemical behavior of $\mathrm{H}$-acceptor copolymer $\mathbf{P 4}$ and its H-bonded side-chain dendritic complexes were investigated by cyclic voltammetry $(\mathrm{CV})$, and the results are summarized in Table 5. The highest occupied molecular orbital (HOMO) and lowest unoccupied molecular orbital (LUMO) levels were calculated according to the following equation: $E_{\mathrm{HOMO}} / E_{\mathrm{LUMO}}=-e\left(E_{\mathrm{ox} / \mathrm{onset}} / E_{\mathrm{red} / \mathrm{onset}}+\right.$ 4.4) $(\mathrm{eV}) .{ }^{52}$ The onset potentials were determined from the intersections of two tangents drawn at the rising and background currents of the CV curves. Since the onsets of the oxidation potentials (i.e., $E_{\text {ox/onset }}$ ) for $\mathrm{H}$-acceptor copolymer $\mathbf{P} \mathbf{4}$ and its $\mathrm{H}$-bonded dendritic complexes were obtained from the $\mathrm{CV}$ measurements, the HOMO (i.e., $E_{\mathrm{HOMO}}$ ) values were calculated from the previous equation, i.e., $E_{\mathrm{HOMO}}=-e\left(E_{\mathrm{ox} / \mathrm{onset}}+4.4\right)$ $(\mathrm{eV})$, where $E_{\text {ox/onset }}$ is the onset oxidation potential versus the saturated calomel electrode (SCE). H-acceptor copolymer P4 and its H-bonded dendritic complexes show the onset potentials of oxidation between 1.24 and $1.27 \mathrm{~V}$ in the anodic scans (see Table 5). The reduction potential peaks of $\mathrm{H}$-acceptor copolymer and $\mathrm{H}$-bonded side-chain dendrimers were not observed in the $\mathrm{CV}$ measurements, so crude estimations of LUMO values in the reduction processes of $\mathrm{H}$-acceptor copolymer $\mathbf{P 4}$ and its $\mathrm{H}$-bonded side-chain dendrimers were made by the deduction 


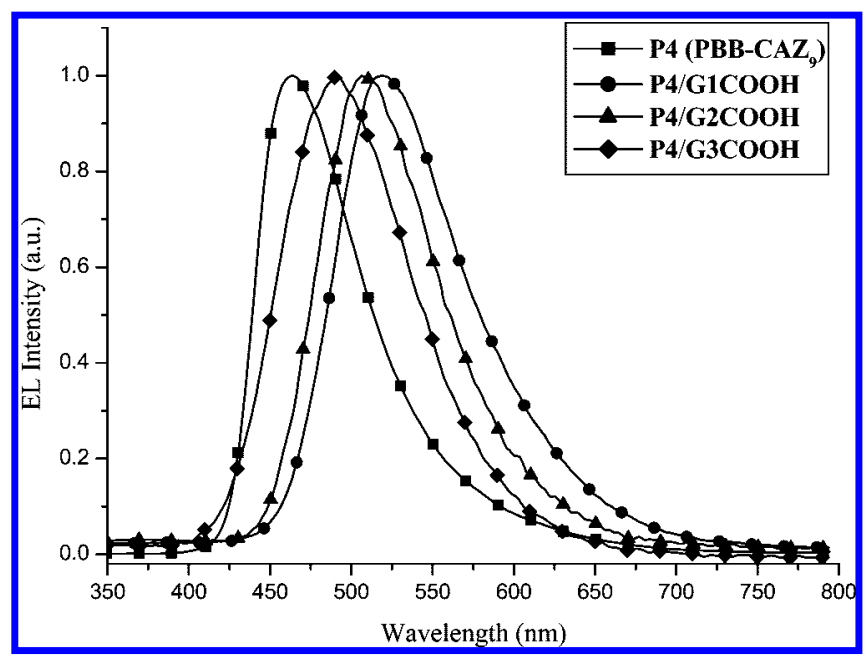

Figure 10. Normalized EL spectra of PLED devices with the configuration of ITO/PEDOT:PSS/polymer (P4 or its H-bonded side-chain dendritic complexes)/BCP/Alq $3 / \mathrm{LiF} / \mathrm{Al}$.

of optical band gap values from HOMO values. The optical band gaps estimated from the absorption onsets of $\mathrm{H}$-acceptor copolymer $\mathbf{P 4}$ and its $\mathrm{H}$-bonded side-chain dendritic complexes in solid films are also listed in Table 5, which reveals that H-acceptor copolymer $\mathbf{P 4}$ has a larger band gap than its H-bonded side-chain dendrimers. Comparing the H-bonded sidechain dendritic complexes with various generations of OXD dendritic wedges, their LUMO values are not remarkably changed. However, it seems that the H-bonded side-chain dendritic complexes have slightly lower LUMO values than $\mathrm{H}$-acceptor copolymer $\mathbf{P 4}$ similar to a previously reported consequence. $^{50 a}$

Electroluminescence (EL) Properties. The electrochemical properties as well as the HOMO and LUMO energy levels of $\mathrm{H}$-acceptor copolymer $\mathbf{P} \mathbf{4}$ and its $\mathrm{H}$-bonded side-chain dendritic complexes are crucial parameters for the device configuration and further confine the electron-hole recombination zone to the emission layer sufficiently. Therefore, $\mathrm{H}$-acceptor polymer P4 and its H-bonded dendritic complexes were fabricated into four-layer PLED devices, with a configuration of ITO/PEDOT: PSS $(50 \mathrm{~nm}) /$ polymer (P4 or its H-bonded dendritic complexes) $(55-70 \mathrm{~nm}) / \mathrm{BCP}(10 \mathrm{~nm}) / \mathrm{Alq}_{3}(30 \mathrm{~nm}) / \mathrm{LiF}(1 \mathrm{~nm}) / \mathrm{Al}(150$ $\mathrm{nm})$ using standard procedures of spin-coating and vacuum deposition methods, where polymer (P4 or its H-bonded dendritic complexes) was used as the emission layer and PEDOT:PSS as the hole transporting layer (anode buffer). Besides, BCP $(\mathrm{HOMO}=-6.70 \mathrm{eV}, \mathrm{LUMO}=-3.20 \mathrm{eV}), \mathrm{Alq}_{3}$ $(\mathrm{HOMO}=-6.00 \mathrm{eV}, \mathrm{LUMO}=-3.30 \mathrm{eV})$, and LiF/Al were employed as a hole-blocking layer, an electron-transporting layer, and a bilayer cathode, respectively. As shown in Figure 10 , under forward bias voltages, the electroluminescence (EL) spectra of $\mathrm{H}$-acceptor polymer $\mathbf{P 4}$ and its $\mathrm{H}$-bonded dendritic complexes show EL emissions in the range of 464-519 nm, indicating that the emission color can be effectively tuned from blue to green by incorporating light-emitting $\mathrm{H}$-acceptor copolymer P4 with various generations of OXD dendritic donors into the supramolecular side-chain polymer structures. These EL features are similar to those observed with corresponding PL emissions of the respective solid films. The electroluminescence (EL) properties of the PLED devices are summarized in Table 6 , and their current-voltage and luminescence-voltage characteristics are displayed in Figure 11. A comparison of their turn-on voltages, the PLED device bearing H-bonded dendritic complex P4/G1COOH, has a lower turn-on voltage than that bearing $\mathrm{H}$-acceptor P4. From this result, it can be concluded that the integration of OXD dendritic wedges (electron-
Table 6. Electroluminescence (EL) Device Performance Characteristics of H-Acceptor Polymer P4 and Its H-Boned Side-Chain Dendritic Complexes ${ }^{a}$

\begin{tabular}{lccccc}
\hline $\begin{array}{c}\text { polymer or } \\
\text { H-bonded } \\
\text { complex }\end{array}$ & $\begin{array}{c}\lambda_{\mathrm{EL}, \mathrm{ilm}} \\
(\mathrm{nm})\end{array}$ & $\begin{array}{c}V_{\text {on }}{ }^{b} \\
(\mathrm{~V})\end{array}$ & $\begin{array}{c}\text { luminance } \\
\text { efficiency } \\
(\mathrm{cd} / \mathrm{A})\end{array}$ & $\begin{array}{c}\text { power } \\
\text { efficiency }^{c} \\
(\mathrm{~lm} / \mathrm{W})\end{array}$ & $\begin{array}{c}\text { max } \\
\text { luminance } \\
\left(\mathrm{cd} / \mathrm{m}^{2}\right)(\mathrm{V})\end{array}$ \\
\hline P4 (PBB-CAZ $)$ & 464 & 8.5 & 0.75 & 0.109 & $947(24)$ \\
P4/G1COOH & 519 & 6.5 & 0.39 & 0.070 & $408(18)$ \\
P4/G2COOH & 506 & 7 & 0.11 & 0.034 & $242(19.5)$ \\
P4/G3COOH & 492 & 8.5 & $-^{d}$ & $-{ }^{d}$ & $58(22)$
\end{tabular}

${ }^{a}$ Device configuration: ITO/PEDOT:PSS/polymer (P4 or its H-bonded side-chain dendritic complexes)/BCP/Alq $3 / \mathrm{LiF} / \mathrm{Al} .{ }^{b} V_{\text {on }}$ : the turn-on voltage of light. ${ }^{c}$ Measured at $100 \mathrm{~mA} / \mathrm{cm}^{2} .{ }^{d}$ Undetectable (less than $100 \mathrm{~mA} / \mathrm{cm}^{2}$ ).

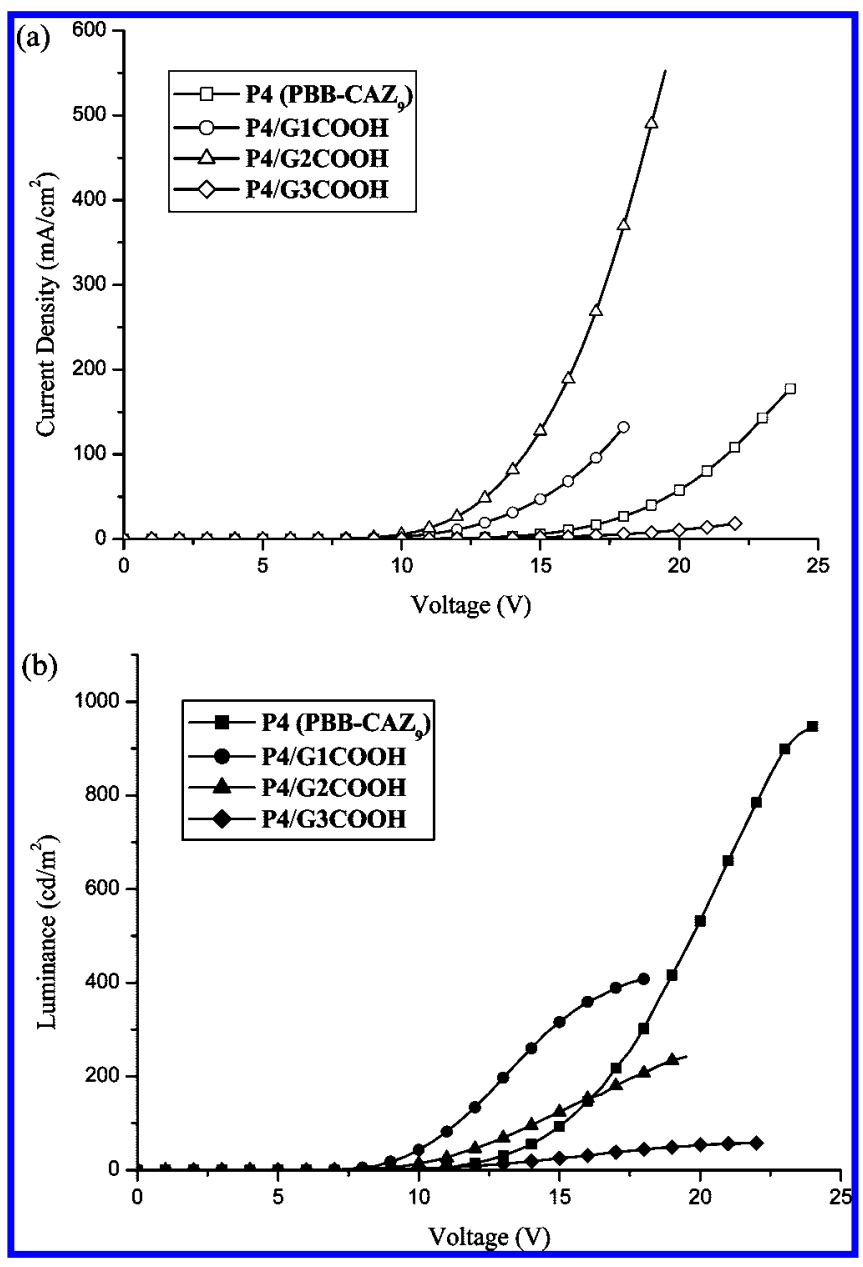

Figure 11. (a) Current density-voltage $(I-V)$ curves and (b) luminance-voltage $(L-V)$ curves of PLED devices with the configuration of ITO/PEDOT:PSS/polymer (P4 or its H-bonded side-chain dendritic complexes)/BCP/Alq $3 / \mathrm{LiF} / \mathrm{Al}$.

transporting) into the supramolecular structures can remarkably improved device performance with a reduced turn-on voltage (though with a lower power efficiency). However, with higher generations (from G1COOH to G3COOH) of OXD dendritic wedges in the supramolecular H-bonded dendritic complexes, the turn-on voltages and power efficiencies of the PLED devices become worse (higher). This may be due to the intrinsic insulation properties of the higher generations of the OXD dendritic wedges with more 2-ethylhexyloxy end groups (as a shielding effect for electron and hole transporting) which consequently deteriorate the charge-carrier transporting properties and lead to higher turn-on voltages. ${ }^{53}$ In addition, the PLED device bearing H-bonded dendritic complex P4/G1COOH has the best EL performance characteristics with a maximum luminance and luminous efficiency of $408 \mathrm{~cd} / \mathrm{m}^{2}$ at $18 \mathrm{~V}$ and 
$0.39 \mathrm{~cd} / \mathrm{A}$ at $100 \mathrm{~mA} / \mathrm{cm}^{2}$, respectively, which are generally better than those of corresponding PLED devices bearing H-bonded dendritic complexes P4/G2COOH and P4/ G3COOH. This could be presumably attributed to the larger dendron shells of the higher generations of OXD H-donors, which have a larger influence on the carrier mobility and trapping process. $^{28,54}$

\section{Conclusion}

A series of novel H-bonded acceptor copolymers containing different molar ratios of hole-transporting carbazole $(\mathbf{C A Z})$ units and light-emitting PBB moieties (bearing three conjugated aromatic rings and a terminal $\mathrm{H}$-acceptor) were successfully synthesized. By the complementary surroundings via the complexation with different generations of OXD dendritic donors (G1COOH-G3COOH), the emission wavelengths of $\mathrm{H}$ acceptor copolymers can be easily adjusted in their selfassembled structures of $\mathrm{H}$-bonded side-chain dendritic complexes. As a result, all light-emitting, hole-transporting, and charge-transporting groups possessing novel photophysical and thermal properties are obtained in the supramolecular side-chain copolymers (i.e., H-bonded side-chain dendritic complexes). Moreover, the incorporation of carbazole units in the acceptor copolymers shows higher glass transition temperatures than the acceptor homopolymer itself, and the emission wavelengths of $\mathrm{H}$-acceptor polymers can be tuned (up to $61 \mathrm{~nm}$ of red shift) by $\mathrm{H}$-bonds. In addition, the larger dendritic size (i.e., the higher generation) of H-donors can afford stronger site-isolation and dendron-dilution effects, and thus better energy-transfer phenomena can be achieved. The PLED devices with the configuration of ITO/PEDOT:PSS/(P4 or its H-bonded dendritic complexes $/ \mathrm{BCP} / \mathrm{Alq}_{3} / \mathrm{LiF} / \mathrm{Al}$ were fabricated, and the emission colors from blue to green can be effectively tuned by incorporating various generations of OXD dendritic donors in the supramolecular side-chain polymer structures.

Acknowledgment. We are grateful to the National Center for High-performance Computing for computer time and facilities. The powder XRD measurements are supported by beamline BL17A (charged by Dr. Jey-Jau Lee) of the National Synchrotron Radiation Research Center (NSRRC), in Taiwan. Prof. Yu-Tai Tao (vacuum deposition) at Institute of Chemistry, Academia Sinica (in Taiwan), is also acknowledged for his instrumental support in the PLED device fabrication. The financial support provided by the National Science Council of Taiwan (ROC) through NSC 95-2113-M-009023 and Chung-Shan Institute of Science and Technology (in Taiwan) is acknowledged for this project.

Supporting Information Available: Experimental details of the XRD installation; ${ }^{1} \mathrm{H}$ NMR spectra and TGA data of monomers M1-M2 and polymers P1-P6; XRD and POM data of homopolymer P1; chemical structure of model compound $\mathbf{1}$ and its emission spectrum overlapped with that of homopolymer P5 as well as overlapped with the absorption spectrum of homopolymer P1. This material is available free of charge via the Internet at http:// pubs.acs.org.

\section{References and Notes}

(1) Lehn, J. M. Supramolecular Chemistrv; Concepts and Perspectives; VCH: Weinheim, Germany, 1995.

(2) (a) Jenekhe, S. A.; Chen, X. L. Science 1999, 283, 372. (b) Whiteside, G. M.; Mathias, J. P.; Seto, C. T. Science 1991, 254, 1312.

(3) Kato, T.; Fréchet, J. M. J. Macromolecules 1989, 22, 3819.

(4) Kato, T.; Kihara, H.; Kumar, U.; Uryu, T.; Fréchet, J. M. J. Angew. Chem., Int. Ed. Engl. 1994, 33, 1644.

(5) Malik, S.; Dhal, P. K.; Mashelkar, R. A. Macromolecules 1995, 28, 2159.

(6) Kato, T.; Kihara, H.; Ujiie, S.; Uryu, T.; Fréchet, J. M. J. Macromolecules 1996, 29, 8734.
(7) (a) Schenning, A. P. H. J.; Jonkheijm, P.; Peeters, E.; Meijer, E. W. J. Am. Chem. Soc. 2001, 123, 409. (b) Ligthart, G. B. W. L.; Ohkawa, H.; Sijbesma, R. P.; Meijer, E. W. J. Am. Chem. Soc. 2005, 127, 810. (c) Roosma, J.; Mes, T.; Leclère, P.; Palmans, A. R. A.; Meijer, E. W. J. Am. Chem. Soc. 2008, 130, 1120.

(8) Medvedev, A. V.; Barmatov, E. B.; Medvedev, A. S.; Shibaev, V. P.; Ivanov, S. A.; Kozlovsky, M.; Stumpe, J. Macromolecules 2005, 38, 2223.

(9) (a) Cheng, Z.; Ren, B.; Shan, H.; Liu, X.; Tong, Z. Macromolecules 2008, 41, 2656.

(10) Canilho, N.; Kasëmi, E.; Schlüter, A. D.; Mezzenga, R. Macromolecules 2007, 40, 2822.

(11) Dinolfo, P. H.; Hupp, J. T. Chem. Mater. 2001, 13, 3113.

(12) McClenaghan, N. D.; Passalacqua, R.; Loiseau, F.; Campagna, S.; Verheyde, B.; Hameurlaine, A.; Dehaen, W. J. Am. Chem. Soc. 2003, $125,5356$.

(13) Chen, Y. Y.; Tao, Y. T.; Lin, H. C. Macromolecules 2006, 39, 8559.

(14) Kimura, M.; Sano, M.; Muto, T.; Hanabusa, K.; Shirai, H. Macromolecules 1999, 32, 7951.

(15) Frein, S.; Auzias, M.; Sondenecker, A.; Vieille-Petit, L.; Guintchin, B.; Maringa, N.; Süss-Fink, G.; Barberá, J.; Deschenaux, R. Chem. Mater. 2008, 20, 1340.

(16) Burroughes, J. H.; Bradley, D. D. C.; Brown, A. R.; Marks, R. N.; Mackay, K.; Friend, R. H.; Burn, P. L.; Holmes, A. B. Nature (London) 1990, 347, 539.

(17) Mitschke, U.; Bäuerle, P. J.Mater. Chem. 2001, 10, 1471.

(18) Kawamoto, M.; Mochizuki, H.; Ikeda, T.; Iino, H.; Hanna, J. I. J. Phvs. Chem. B 2005, 109, 9226.

(19) Johansson, D. M.; Srdanov, G.; Yu, G.; Theander, M.; Inganas, O.; Anderson, M. R. Macromolecules 2000, 33, 2525.

(20) Zaumseil, J.; Sirringhaus, H. Chem. Rev. 2007, 107, 1296.

(21) (a) Greenham, N. C.; Moratti, S. C.; Bradley, D. D. C.; Friend, R. H.; Holmes, A. B. Nature (London) 1993, 365, 628. (b) Burn, P. L.; Kraft, A.; Baigent, D. R.; Bradley, D. D. C.; Brown, A. R.; Friend, R. H.; Gymer, R. W.; Holmes, A. B.; Jackson, R. W. J. Am. Chem. Soc. 1993, 115, 10117.

(22) Marsitzky, D.; Vestberg, R.; Blainey, P.; Tang, B. T.; Hawker, C. J.; Carter, K. R. J. Am. Chem. Soc. 2001, 123, 6965.

(23) (a) Setayesh, S.; Grimsdale, A. C.; Weil, T.; Enkelmann, V.; Müllen, K.; Meghdadi, F.; List, E. J. W.; Leising, G. J. Am. Chem. Soc. 2001, 123, 946. (b) Pogantsch, A.; Wenzl, F. P.; List, E. J. W.; Leising, G.; Grimsdale, A. C.; Müllen, K. Adv. Mater. 2002, 14, 1061. (c) Oesterling, I.; Müllen, K. J. Am. Chem. Soc. 2007, 129, 4595.

(24) Kwok, C. C.; Wong, M. S. Chem. Mater. 2002, 14, 3158.

(25) Kimoto, A.; Masachika, K.; Cho, J. S.; Higuchi, M.; Yamamoto, K. Chem. Mater. 2004, 16, 5706.

(26) Pillow, J. N. G.; Halim, M.; Lupton, J. M.; Burn, P. L.; Samuel, I. D. W. Macromolecules 1999, 32, 5985.

(27) Kwon, T. W.; Alam, M. M.; Jenekhe, S. A. Chem. Mater. 2004, 16, 4657.

(28) (a) Kimura, M.; Sato, M.; Adachi, N.; Fukawa, T.; Kanbe, E.; Shirai, H. Chem. Mater. 2007, 19, 2809.

(29) Ma, C.-Q.; Mena-Osteritz, E.; Debaerdemaeker, T.; Wienk, M. M.; Janssen, R. A. J.; Bauerle, P. Angew. Chem., Int. Ed. 2007, 46, 1679.

(30) Taranekar, P.; Fulghum, T.; Patton, D.; Ponnapati, R.; Clyde, G.; Advincula, R. J. Am. Chem. Soc. 2007, 129, 12548.

(31) Burm, P. L.; Lo, S. C.; Samuel, I. D. W. Adv. Mater. 2007, 19, 1675.

(32) (a) Precup-Blaga, F. S.; Garcia-Martinez, J. C.; Schenning, A. P. H. J.; Meijer, E. W. J. Am. Chem. Soc. 2003, 125, 12953. (b) Schenning, A. P. H. J.; Peeters, E.; Meijer, E. W. J. Am. Chem. Soc. 2000, 122, 4489.

(33) Zhao, Z.; Xu, X.; Wang, H.; Lu, P.; Yu, G.; Liu, Y. J. Org. Chem 2008, 73, 594 .

(34) (a) Bo, Z.; Zhang, C.; Severin, N.; Rabe, J. P.; Schlüter, A. D. Macromolecules 2000, 33, 28-2688. (b) Fu, Y.; Li, Y.; Li, J.; Yan, S.; Bo, Z. Macromolecules 2004, 37, 6395. (c) Zhu, B.; Han, Y.; Sun, M.; Bo, Z. Macromolecules 2007, 40, 4494.

(35) Lo, S. C.; Burn, P. L. Chem. Rev. 2007, 107, 1097.

(36) Köse, M. E.; Mitchell, W. J.; Kopidakis, N.; Chang, C. H.; Shaheen, S. E.; Kim, K.; Rumbles, G. J. Am. Chem. Soc. 2007, 129, 14257.

(37) Wu, C. W.; Lin, H. C. Macromolecules 2006, 39, 7985.

(38) Eaton, D. Pure Appl. Chem. 1998, 60, 1107.

(39) Lin, D. G.; Lin, G. Q. Tetrahedron Lett. 1999, 40, 337.

(40) (a) Okawara, R.; Wada, M. J. Organomet. Chem. 1963, 1, 81. (b) Wada, M.; Nishino, M.; Okawara, R. J. Organomet. Chem. 1965, 3, 70.

(41) Engels, C.; Steenwinckel, D. V.; Hendrickx, E.; Schaerlaekens, M.; Persoons, A.; Samyn, C. J. Mater. Chem. 2002, 12, 951.

(42) Hathaway, B. A.; Taylor, B. E.; Wittenborn, J. S. Synth. Commun. $1998,28,4629$.

(43) (a) Arbuzov, B. A. Pure Appl. Chem. 1964, 9, 307. (b) Michaelis, A.; Kaehne, R. Chem. Ber. 1898, 31, 1048. 
(44) (a) Horner, L. Chem. Ber. 1958, 83, 733. (b) Wadsworth, W. S.; Emmons, W. D. J. Am. Chem. Soc. 1961, 83, 1733.

(45) Sonogashira, K.; Tohda, Y.; Hagihara, N. Tetrahedron Lett. 1975, 4467.

(46) Cui, L.; Lattermann, G. Macromol. Chem. Phys. 2002, 203, 2432.

(47) Lin, H. C.; Hendrianto, J. Polymer 2005, 46, 12146.

(48) (a) Kumar, U.; Kato, T.; Fréchet, J. M. J. J. Am. Chem. Soc. 1992, 114, 6630. (b) Kato, T.; Fréchet, J. M. J.; Wilson, P. G.; Saito, T.; Uryu, T.; Fujishima, A.; Jin, C.; Kaneuchi, F. Chem. Mater. 1993, 5, 1094. (c) Kato, T.; Kihara, H.; Uryu, T.; Fujishima, A.; Fréchet, J. M. J. Macromolecules 1992, 25, 6836.

(49) (a) Kong, X.; Tang, B. Z. Chem. Mater. 1998, 10, 3352. (b) Lam, J. W. Y.; Dong, Y.; Law, C. C. W.; Dong, Y.; Cheuk, K. K. L.; Lai, L. M.; Li, Z.; Sun, J.; Chen, H.; Zheng, Q.; Kwok, H. S.; Wang, M.; Feng, X.; Shen, J.; Tang, B. Z. Macromolecules 2005, 38, 3290.
(50) (a) Wu, C. W.; Tsai, C. M.; Lin, H. C. Macromolecules 2006, 39 , 4298. (b) Wu, C. W.; Sung, H. H.; Lin, H. C. J. Polvm. Sci., Part A: Polvm. Chem. 2006, 44, 6765.

(51) (a) Lin, H. C.; Sheu, H. Y.; Chang, C. L.; Tsai, C. J. Mater. Chem. 2001, 11, 2958.

(52) Leeuw, D. M.; Simenon, M. M. J.; Brown, A. R.; Einerhand, R. E. F. Synth. Met. 1997, 87, 53.

(53) Zhao, L.; Li, C.; Zhang, Y.; Zhu, X. H.; Peng, J.; Cao, Y. Macromol. Rapid Commun. 2006, 27, 914.

(54) Qu, J. Q.; Zhang, J. Y.; Grimsdale, A. C.; Müllen, K.; Jaiser, F.; Yang, X. H.; Neher, D. Macromolecules 2004, 37, 8297.

MA801005C 